Journal of Educational

and Psychological Sciences

Volume (5), Issue (46) : 30 Nov 2021

P: $43-64$
AJSRP

ISSN: 2522-3399

$$
\text { التربوية والنفسية العلوم }
$$

المجلد (5)، العدد (46) : 30 نوفمبر 2021 م

ص: 43 - 404

\title{
The effect of parents' presence on improving personal and social behavior in children (4-16) during and after the home quarantine period during the
}

\section{Corona pandemic in Jordan}

\author{
Ahmad Nayel Algrair \\ Umm Al-Qura University $\|$ KSA \\ Maysra Abdel-Raheem Fayyad \\ Jordan University || Jordan
}

\begin{abstract}
The study aimed to reveal the importance and impact of the presence of parents at home during the Corona pandemic-Covid-19, as they are responsible for raising children, as the study sample reached (368) parents and used a questionnaire of personal and social behavior (20) paragraphs distributed in two dimensions and designed specifically for the purposes of the current study and an appropriate degree of Honesty and constancy, and the results indicated the importance of the presence of parents with children during crises and the Corona pandemic crisis-Covid-19in particular, and the study showed an impact and improvement in the personal and social behavior of children during the quarantine period, and they showed more commitment and awareness than before, in addition to developments in the environmental dimension, the study and training studies the level of awareness of children in these crises and the phenomenon of study. Involving them in activities and tasks and interacting with them and not leaving them without monitoring their presence at home.
\end{abstract}

Keywords: Personal and social behavior, children, parents.

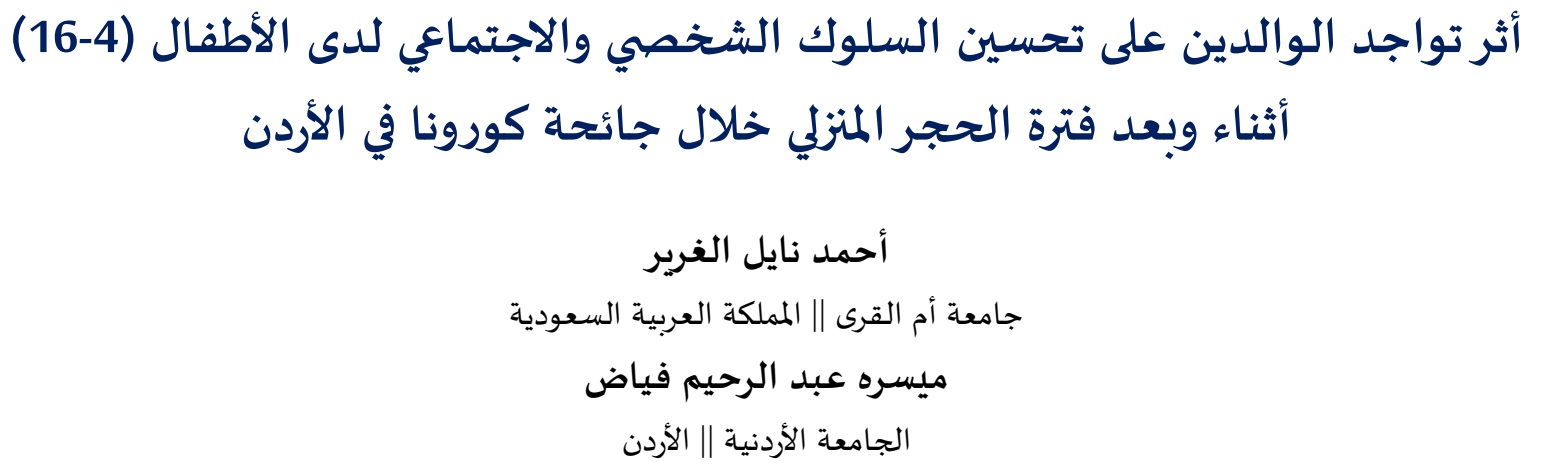

\footnotetext{
المستخلص: هدفت الدراسة إلى الكشف عن أهمية وأثر وجود الوالدين في المنزل أثناء جائحة كورونا باعتبارهم المسؤولين عن تربية

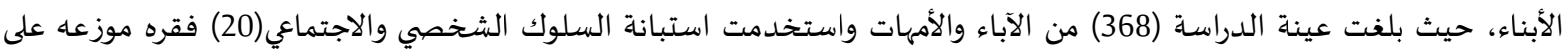

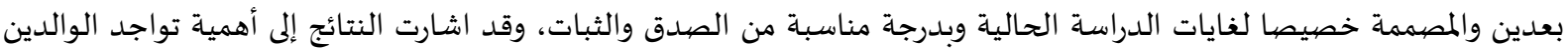

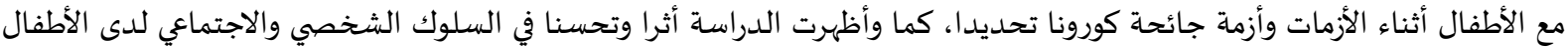

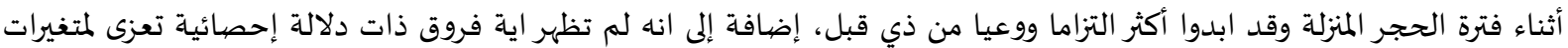

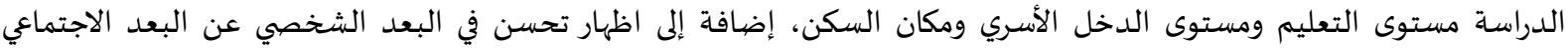


وبدرجة بسيطة، واوصت الدراسة بضرورة التركيز على التدريب ورفع مستوى الوعي عند الأطفال في مثل تلك الأزمات وضرورة اشراكهم بالأنشطة والمهمات والتفاعل معهم وعدم تركهم بدون متابعة أدروكة أثناء تواجدهم في المنازل. الكلمات المفتاحية: السلوك الشخصي والاجتماعي، الأطفال، الوالدين.

مقدمة.

تتعدد الأزمات العالمية التي تجتاح البلدان المختلفة على أشكال عدة من كوارث وزلازل وأوبئة ومجاعات وأمراض تفتك بالبشرية والكائنات الحية، ويواجه العالم في العصر الحالي اضرارا بالغة وجسيمة اقتصادية التهادية

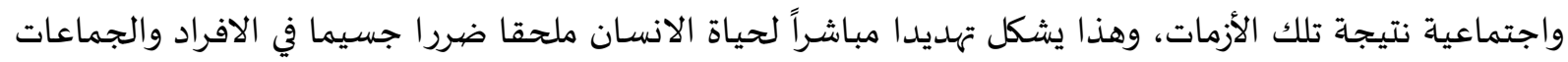

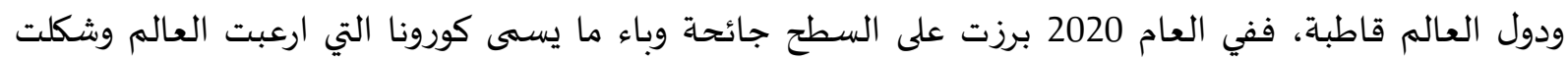

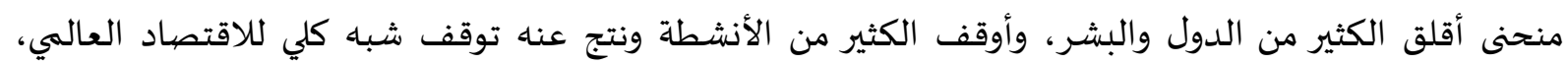

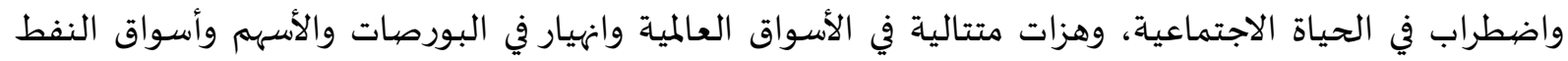

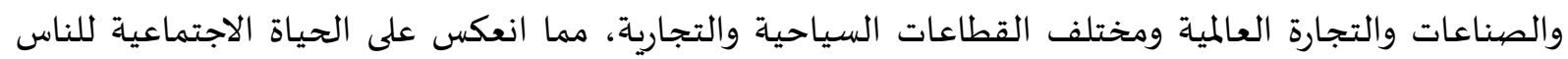

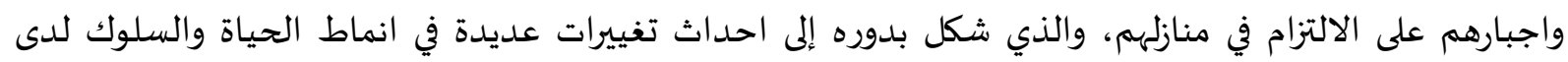

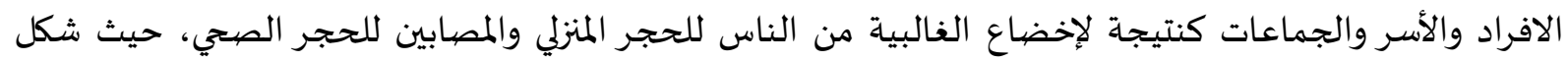

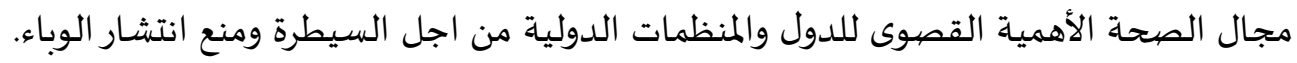

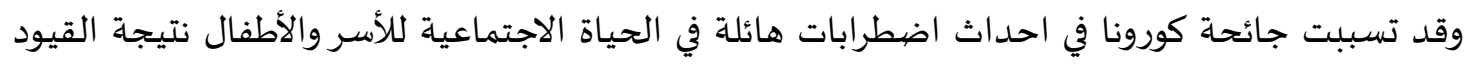
التي فرضت على السفر وتعطيل المدارس وعدم الخروج للأسواق والتجمعات والحفلات والمناسبات والفعاليات والرحلات، حيث تم التركيز على الاسر والأطفال والطلبة لتجنب أية أضرار محتملة التحروجة عليهم.

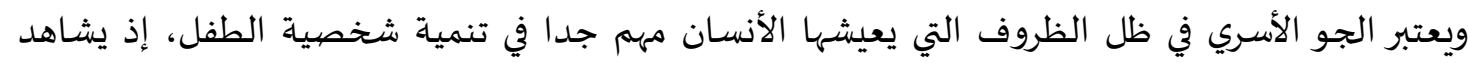
الطفل انماطا مختلفة من السلوك ويلاحظ تصرفات وافعال الوالدين ومن هنا يتكون سلوك وشخصية الطية الطفل

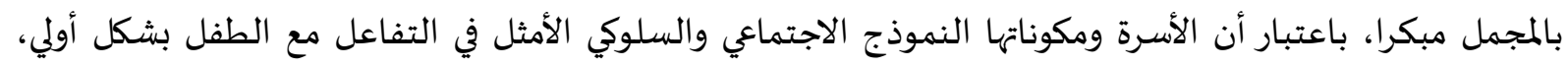

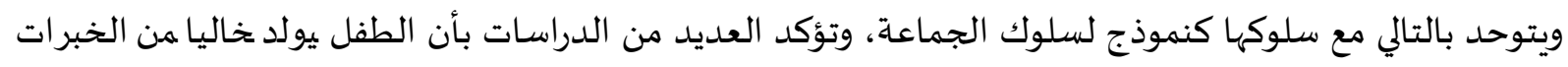

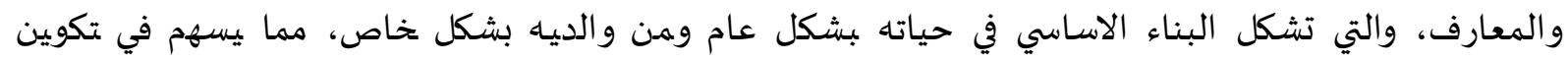

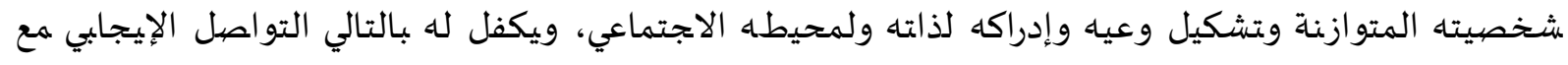

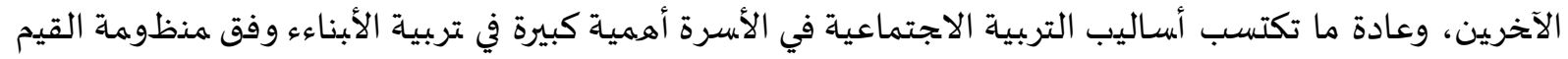

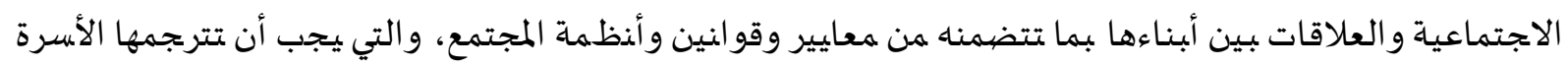

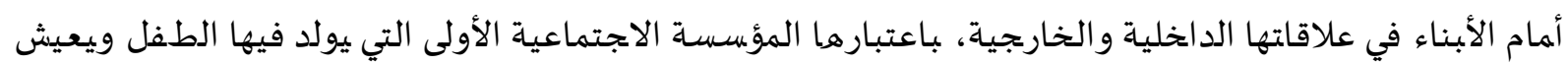

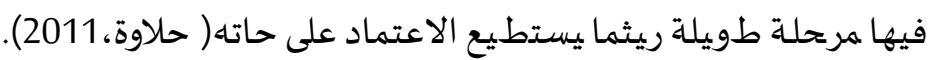

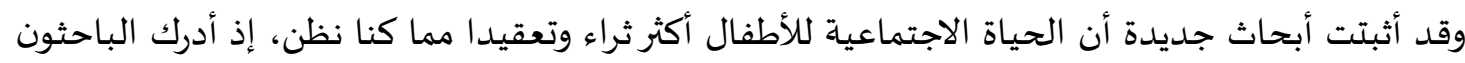

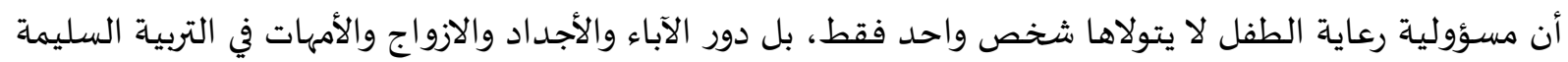

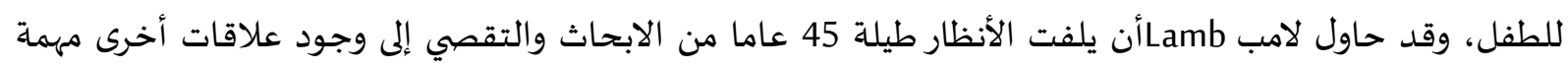

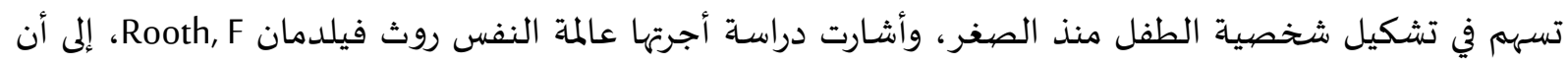

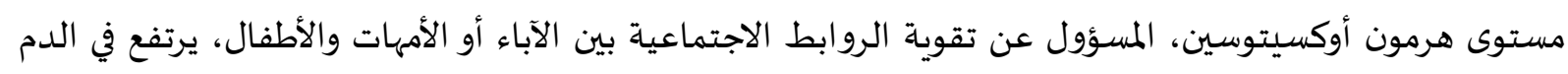

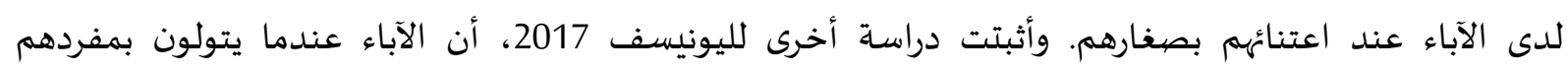

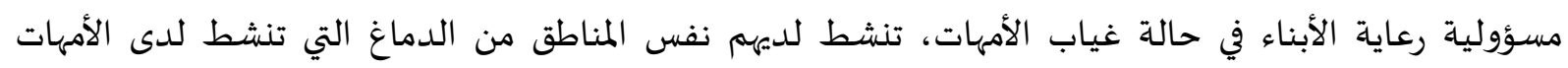




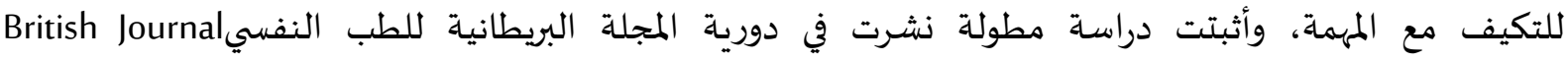
Psychiatric

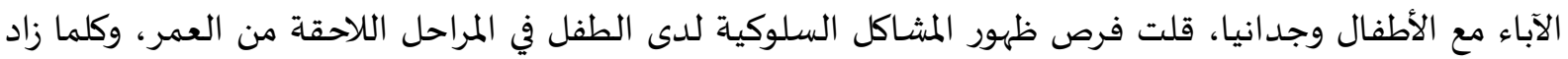

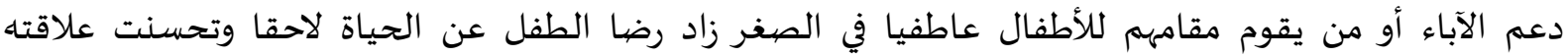

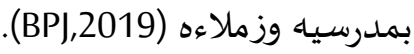

مشكلة البحث: - مش تعدد الأسرة الخلية الأولى في البذاء الاجتماعي حيث يكتسب الإنسان معارفه وخبراته وسلوكياته

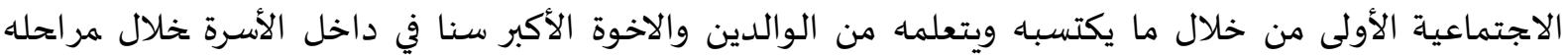

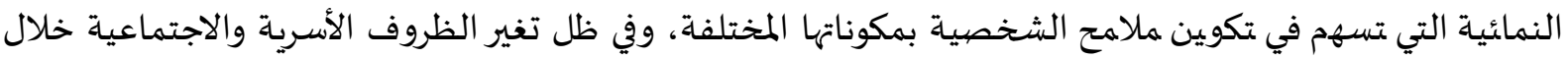

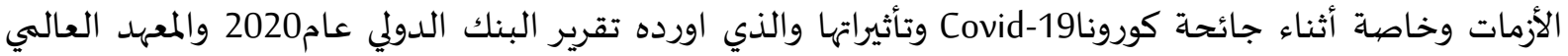

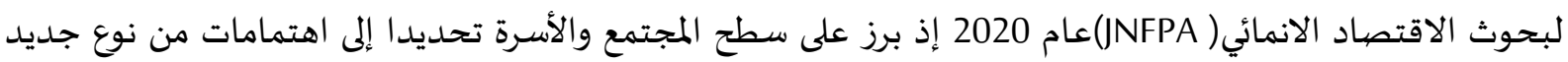

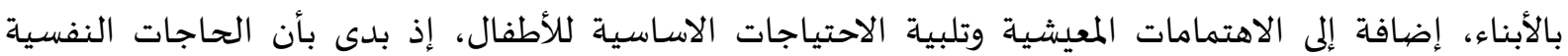

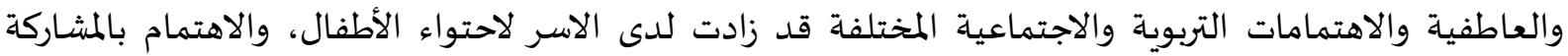

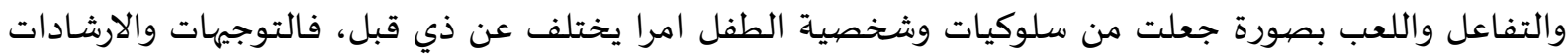
والتعليمات والإيجابيات اصببحت تتفاعل داخل الأسرة بصورة أكثر إيجابية.

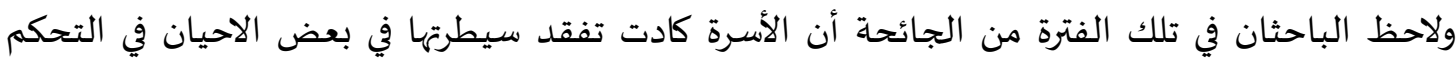

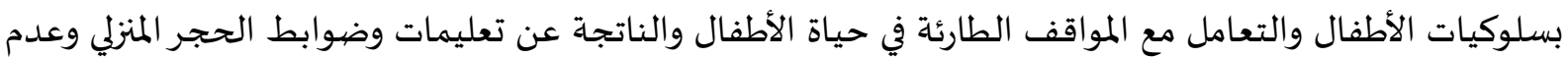

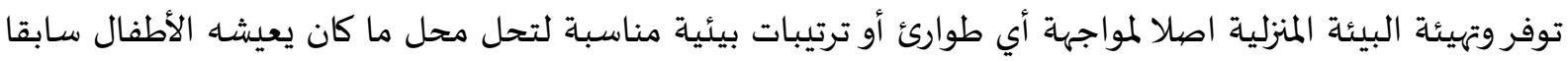

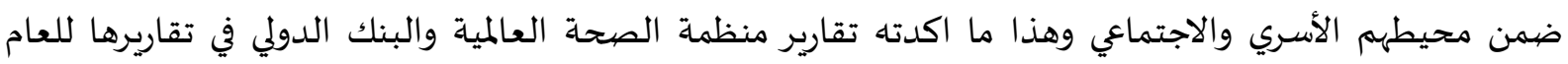

من هنا برز وجود مشكلة تتعلق باليات التعامل مع الأطفال وضبط سلوكياتهم والتي تراوحت بين الشدة واللين من خلال ما كنا نسمع ونشاهد من مواقف واحداث احيانا، وبذلك رأينا كباحثين انه من الواجب من دراسية

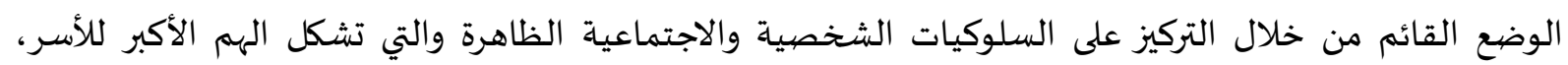

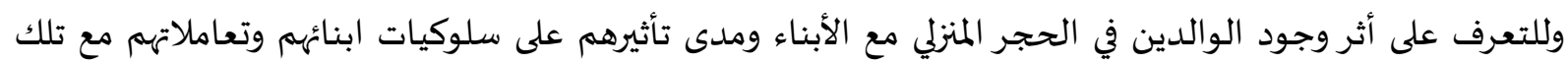

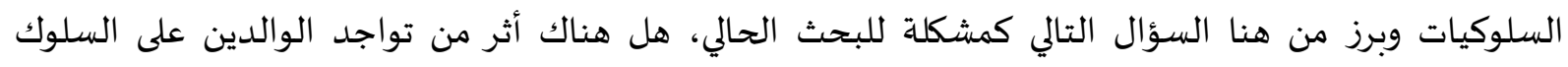

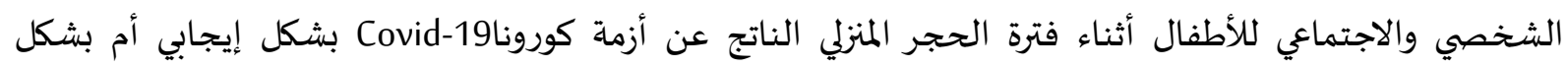

أسئلة الدراسـة: ne

بناء على ما سبق؛ يمكن صياغة مشكلة الدراسة في السؤال الرئيس الآتي:

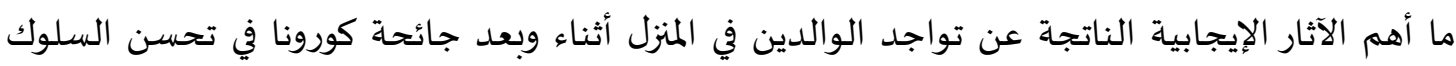
الشخصي والاجتماعي للأبناء؟ ما الإباء

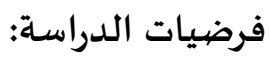
وقد انبثق عن التساؤل الرئيسي في الدراسة الفرضيات التالية: 
1. لا توجد فروق ذات دلالة إحصائية لأثر تواجد الوالدين في المنزل على السلوك الشخصي للأبناء تعزى لمتغير مكان السكن محافظة عمان ومحافظات اخرى. 2. لا توجد فروق ذات دلالة إحصائية لأثر تواجد الوالدين في المنزل على السلوك الشخصي تعزى إلى المستوى التعليمي للأبناء جامعي فأعلى أو أدني. 3. لا توجد فروق ذات دلالة إحصائية لأثر تواجد الوالدين في المنزل على السلوك الشخصي للأبناء تعزى لمتغير الدخل الأسري أكثر من 500 دينار أو أقل.

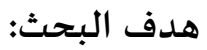

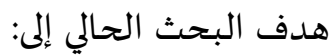

1- التعرف على الواقع الأسري والأبناء وأثر تلك الأزمة وتداعياتها عليهم.

2- الكشف عن أهمية وجود الوالدين في المنزل أثناء الجائحة، باعتبارهم المسؤولين عن تربية الأبناء، وتعزيز شخصية الطفل وكفاءتها في الحياة، لتجاوز أزمات ومواقف قد تؤدي إلى اختلالات في السلوكيات أو في تربية الأطفال، وأهمية الأثر الذي تركه تواجد الوالدين مع أطفالهم في المنزل. 3- بيان اية فروق بين المتغيرات المختلفة وارتباطاتها بتلك الأزمة، والانتفاع من النتائج لوضع برامج وانشطة تتوافق مع مجمل الأزمات التي تمر على الانسان وخاصة الأطفال، وبما ينفع للتخطيط للأزمات الانسانية

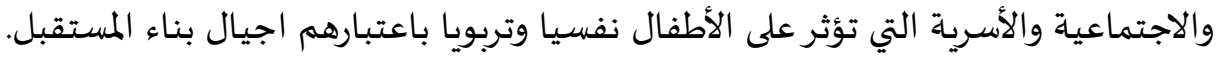

أهمية دراسة:

تحدث في سلوكيات الأطفال تغيرات مع مرور الزمن وحسب الظروف من هنا يرى الباحثان أن الظروف التي تحدث بمرور الزمن، وطبيعة شخصية الطفل تحدث فيها تغييرات كثير ويؤثر فيها كل من الوالدين والاخوة والمحيطين بالطفل من البيئة الخارجية والمدرسية بصورة أكثر وضوحا، ومع بروز جائحة كورونا والحجر المنزلي وتعطيل المدارس

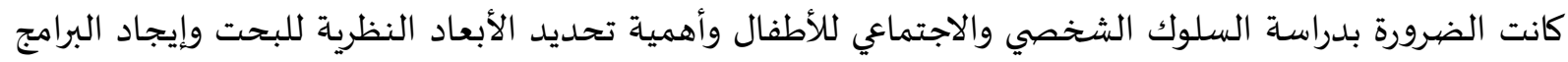
العملية والتطبيقية لمحاولة تجاوز الأزمة وما تركته من تأثيرات على شخصية الأطفال واسرهم ورفع مستو الوعي بمختلف ظروف الوباء وتعديل السلوك بصورة أكثر إيجابية. متغيرات البحث: مكان السكن عمان/ محافظات ودخل الأسرة أكثر أو أقل من 500 ومستوى التعليم جامعي أكثر أو أقل. 2- 2 - الإطار النظري والدراسـات السابقة. أولاً - الإطار النظري: واجه الآباء والأمهات في الأردن أثناء وبعد أزمة كورونا تحديات مشتركة في التعامل مع تربية وتعليم ابنائهم

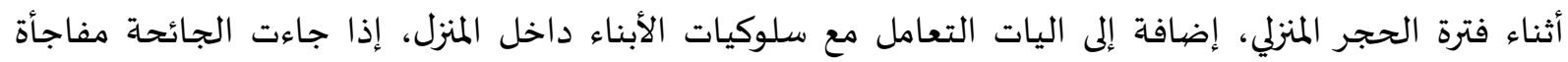

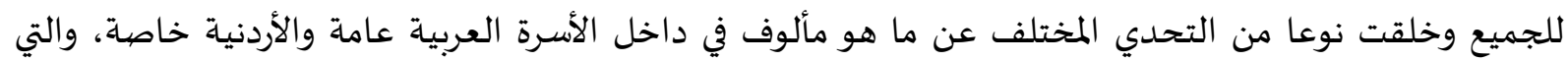
تعاملت مع الوضع الوبائي بشكل منضبط والالتزام بتعليمات الحظر الشامل الذي فُرض على مالى جميع المواطنين. 
وتعد أزمة جائحة فيروس كوروناCovid-19 في الأردن من الاوبئة التي خلقت أزمة حقيقية في الأردن

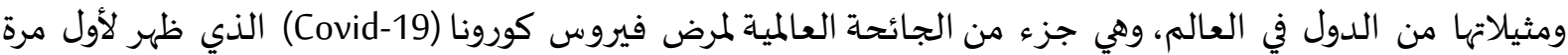
أواخر العام 2019 في الصين وانتشر منها لاحقًا لمعظم دول العالم، أما مُسبب المرض فهو فيروس فئمس من سلالة كورونايُعرف بـ فيروس كورونا 2 المرتبط بالمتلازمة التنفسية الحادة الشديدة(SARS-CoV-2) 》، وبعد أربعة أشهر تقريبًا من بداية المرض سُجّلت أول حالة إصابة مؤكدة بالفيروس داخل البلاد بتاريخ 2 مارس 2020، وعليه اتخذت الأردن إجراءات استباقية لمنع وصول الوباء إلى أراضيها منذ لحظة الإعلان عن انتشاره خارج الصين وتسجيل حالات إصابات ووفيات في دول مختلفة من العالم، وقد فعلت الأردن قانون الدفاع الوطني الصادر عام 1992 وبتعطيل جميع المؤسسات والقطاعات المختلفة كما منعت الحكومة التجمعات لأكثر من 10 أشخاص، ومنعت التنقل بين المحافظات، وتم تعليق العمليات والمراجعات الطبية وزيارة المرضى إلا في حالات وتفعيل عمليات الطوارئ لكافة الاجهزة الضرورية، وأوقفت طباعة الصحف الورقية، باعتبار انها تساهم في انتقال العدوى، وتم تعليق عمل وسائل النقل الجماعي والنقل الجوي وحركة الطائرات والمواصلات وإغلاق المولات والمراكز التجارية، والسماح فقط بفتح مراكز التموين والصيدليات والمخابز والمواد الغذائية والدواء والماء والوقود والكهرباء واقامت الحكومة الأردنية أيضا معسكرات حجر صيحي للقادمين من المعابر الحدودية البرية. وأظهرت نتائج مسحين سريعين أجراهما برنامج الأمم المتحدة الإنمائي (UNDP) في الأردن أن جائحة كورنا

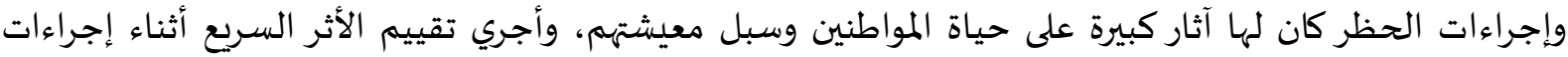

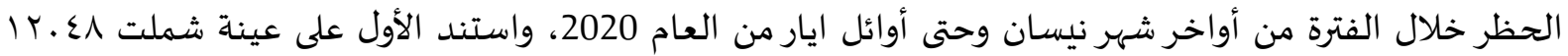

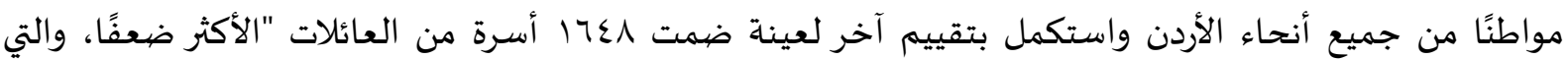

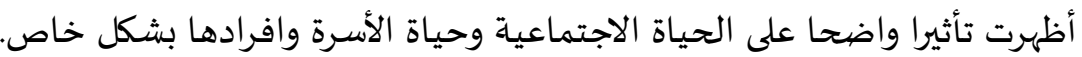
وتعد التربية الأسرية الإيجابية امرا هاما، لضمان التنشئة السليمة للطفل وتعد عنصرا أساسيا في تنشئة الطفل، حيث تعتبر السنوات الأولى التي يقضيها الطفل في منزله من أكبر المؤثرات المسئولة عن تشكيل مستقبله، الطبها

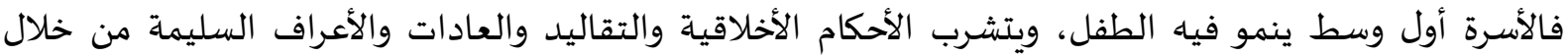

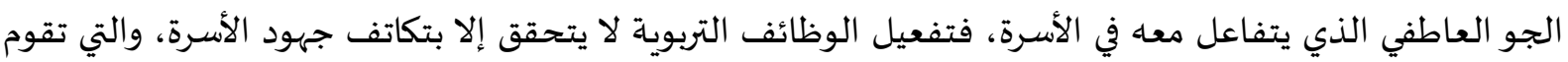

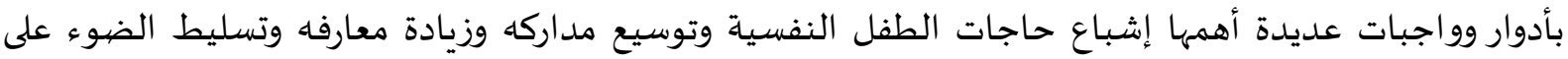
تصرفاته وتصحيحها قدر الامكان(Kerby T. Alvy, 2008). وكثيرة هي الأسر التي تهتم بتربية أطفالها تربية علمية حديثة منا يراها الباحثان، وتدرك جيدان الهاندا أن التربية

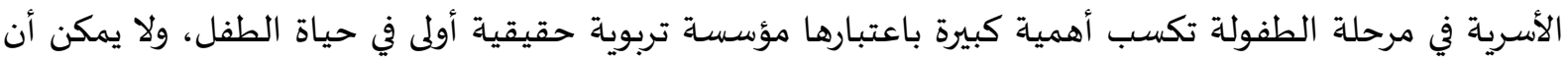

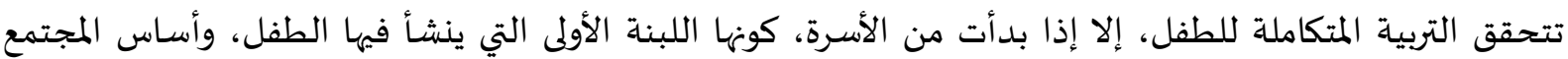

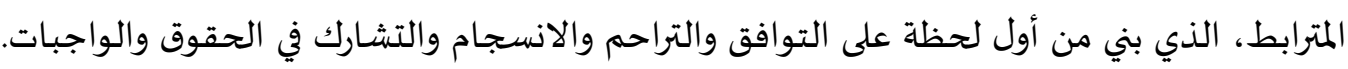

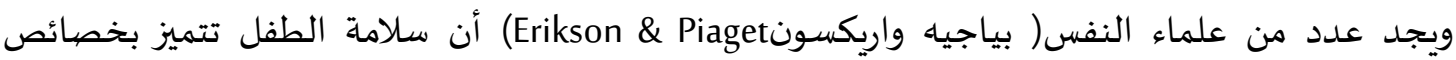
جسمية وعقلية وانفعالية واجتماعية وخلقية وعلى الأسرة أن تقوم بالعمل على تقويم سلوك الأطفال وتعديله،

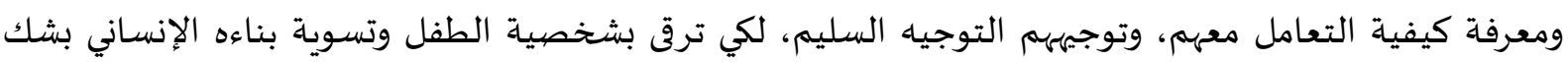

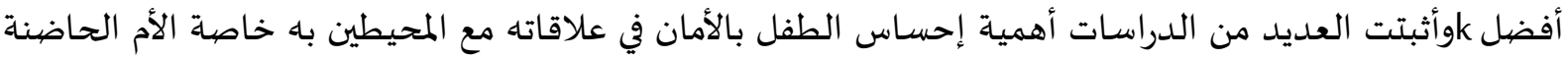

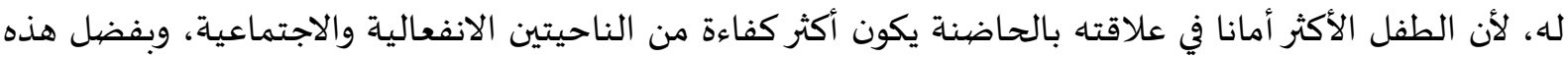
الكفاءة والنضج يستطيع أن يدخل كطرف إيجابي في أي تفاعل اجتماعي مع الآخرين وأثبتت الكثير من الدراسات 
كذلك أهمية النمو النفسي الاجتماعي، والإجراءات المتبعة من الوالدين لحماية أطفالهم في تنمية الجوانب المختلفة بشكل مناسب (Jane B. Brooks, 2012).

ومن أهم العلماء الذين تناولوا النمو النفسي الاجتماعي إريك إريكسون مراحل للتطور والنمو، وذلك من خلال علاقة الفرد ورغباته بالثقافة، وتتحدد كل مرحلة منها بما يطلق عليه الأزمة وأساس هذه الأزمة ما يحدث من تغيرات فسيولوجية وسيكولوجية وثقافية، تسبب مشاكل لابد من حلها في كل

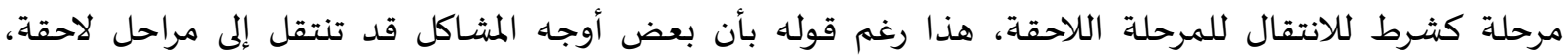

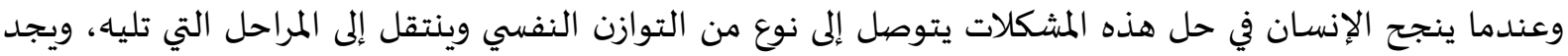

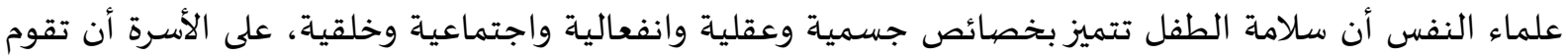
بالعمل على تقويم سلوك الأطفال وتعديله، ومعرفة كيفية التعامل معهم، وتوجيههم التوجيه السليم، لكي نرقى

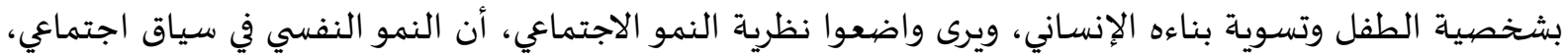

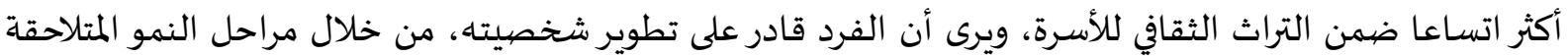
وطيلة حياته، كما ويعتقد بوجود فترات حرجة للنمو، ويعتبرها نقطة تحول حاسمة، وإذا لم تحل مشاكل هذه

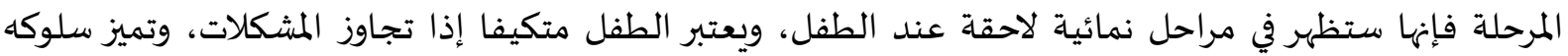

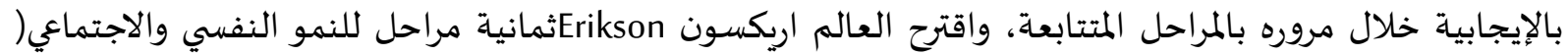
صففاء سعيد،2020). ويؤكد الباحثان بأن العمل الجاد والواعي من قبل الوالدين في تربية الأبناء سيكون له بالغ الأثر في تكيف

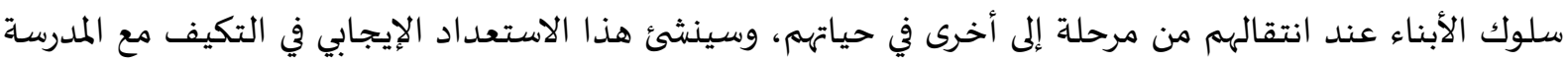

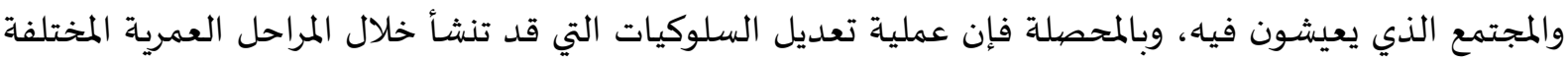

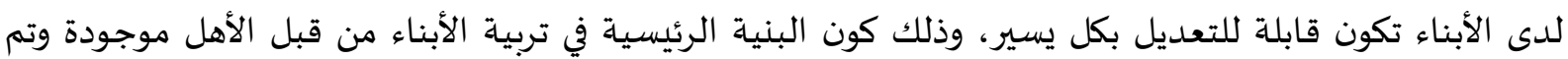
العمل عليها منذ الطفولة المبكرة. وتوصل الباحثان إلى خلاصة بانه إذا كانت الأسرة هي المؤسسة التربوية الأولى التي ينشأ فيها الطفل ويتعلم

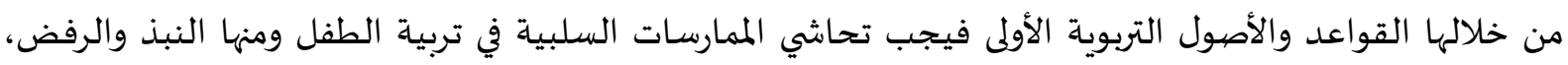

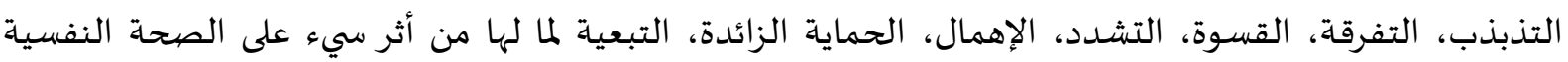

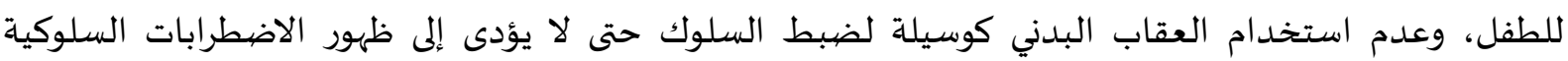
والصراعات والتوتر النفسي لدى الطفل، وأيضاً ضرورة إشباع حاجات الطفل من الحب والحنان والأمن والاستقلال والتقدير حتى يتمتع بصحة نفسية سوية.

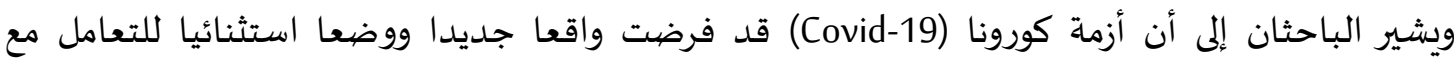

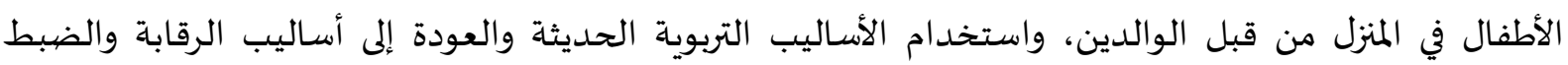

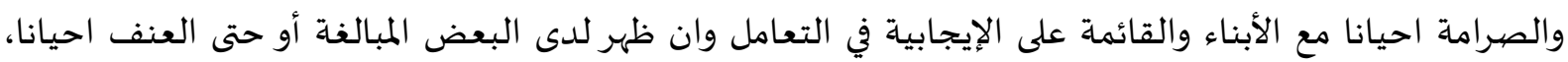

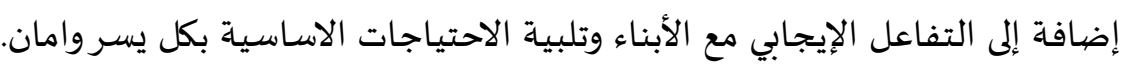

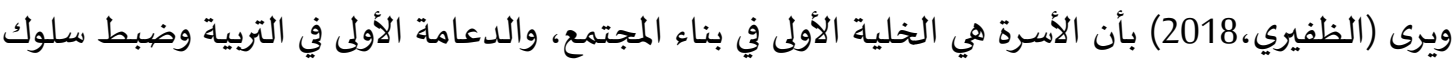

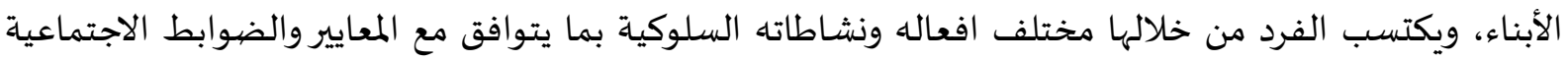
التي تفرضها ثقافة وعادات وتقاليد وقيم المجتمع الذي يعيش فياه، كذلك يؤكد على أن أساليب التربية التي تتراوح

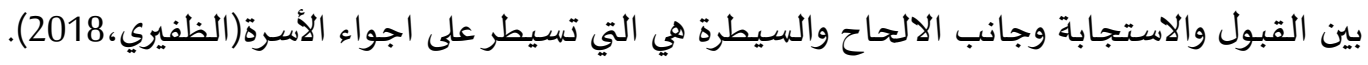


وتشير الفرخ وتيم، 1999 إلى أن الأسرة تلعب دورا في التنشئة النفسية للطفل من خلال تأثيرها على مظاهر النمو النفسي وعلى نمو شخصية الطفل بشكل عام إضافة إلى كافة مظاهر النمو الانفعالي والعقلي والاجتماعي، وان الخبرات التي يتعرض لها الطفل في مرحلة الطفولة تؤثر على سلوكاه وانفعالاته، وعلى الوالدين أن يعاملوا ابنائهم معاملة إيجابية واعتبارهم مشاركين متفاعلين في كل شيء لتصبح حياته أكثر سعادة وامانا، إضافة إلى تنمية

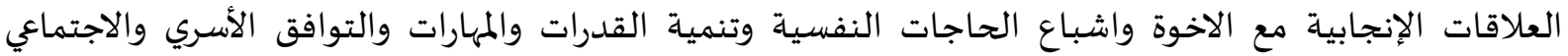
بصورة افضل( الفرخ وتيم، 1999). وتشير (الفوارس، 2013) إلى مراعاة أساس التدرج في تشكيل سلوكيات افرادها، وتخليصهم من السلوك غير المرغوب فياه، وذلك من خلال مراعاة الأسرة لسمة التكامل بين القدرات العقلية والجسمياة، في ضوء نمو افرادها عبر المراحل العمرية المختلفة، وأن تعمل الأسرة على إشاعة روح الفكاهة بين افرادها، وذلك بطرح القضايا والموضوعات التي تتطلب تفكيراً أولويا، ويتدربون على حسن التعامل مع الاخرين وفيما بينهم، إضافة إلى تحقيق الذات لدى

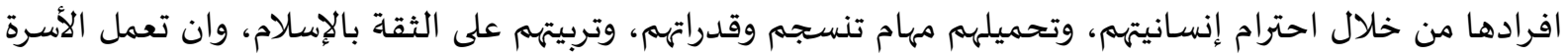
على احترام إرادة كل فرد من افرادها، وعدم حملهم على الأفعال بالإكراه والإجبار وقيام العلاقات بين افرادها على

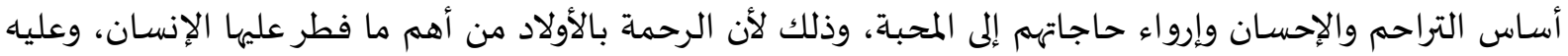

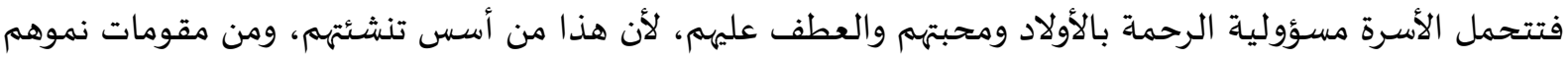

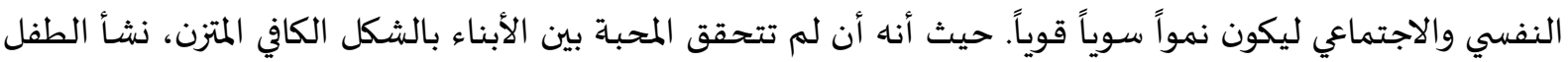

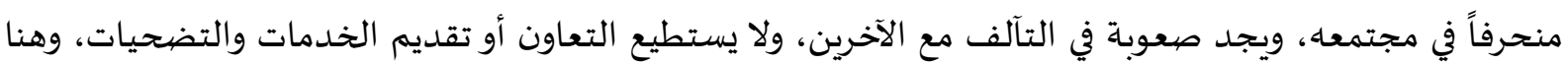

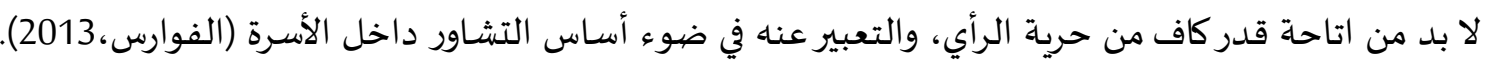

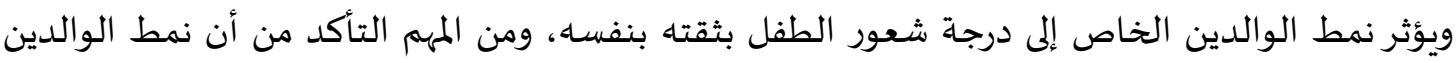
يدعم النمو والتطور بشكل إيجابي لأن الطريقة التي تتفاعل بها الأسرة والمحيطين مع الطفل ستؤثر عليه طوال حياته سلبا أو إيجابا(Nelson,F.2016). وقد حدد الباحثون(Matejevic M,Todorovic J,Jovanovic A.D(2014 عدة أنواع من أساليب التربية الوالدياة: آباء مستبدون Authoritarian: وهنا الأطفال الذين يكبرون مع آباء مستبدين صارمين يميلون إلى اتباع

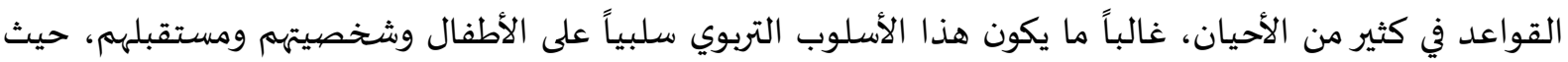
يواجه الأطفال الذين يخضعون للاستبداد العائلي صعوبة في تكوين علاقات اجتماعية سوية وصحية، الإناء آباء رسميون: وهنا يميل الأطفال الذين يتم تربيتهم من خلال الانضباط الرسمي إلى أن يكونوا سعداء وناجحين، كما أههم أكثر

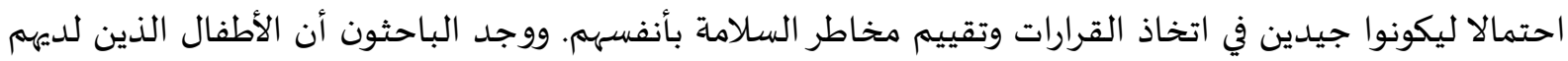

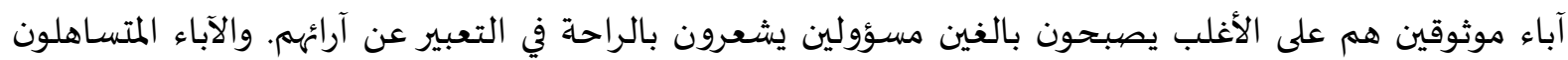
Permissive

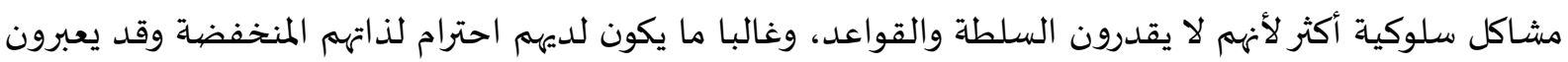

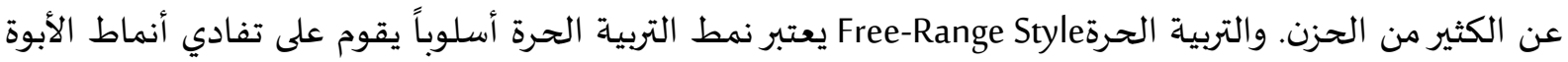

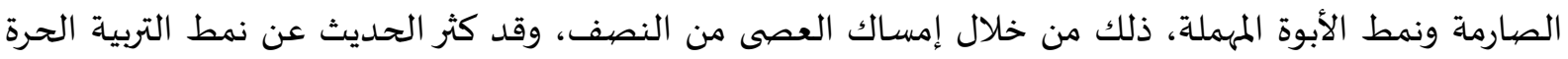

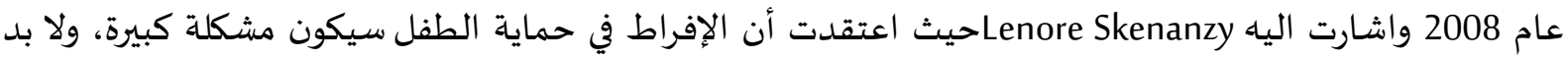

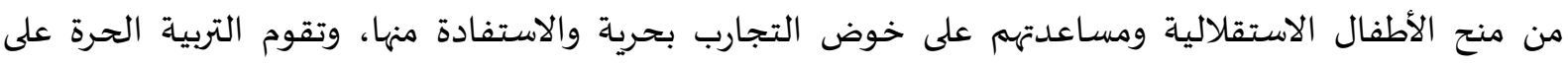

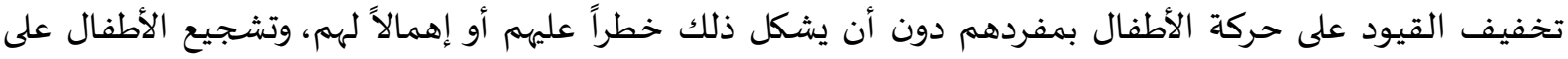


اللعب في الأماكن المفتوحة ومع أقرانهم أكثر من الألعاب الالكترونية والمنزلية، وتحميل الأطفال مسؤولية أنفسهم بشكل معتدل مع منحهم الاستقلالية(Sigelman,c\& Rider,E.2015). خلاصة القول من وجهة نظر الباحثان، انه مهما اختلفت وجهات النظر حول طرق وأساليب التربية وأنماط

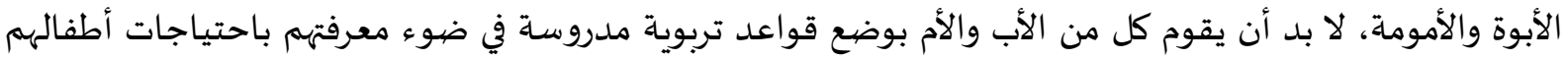

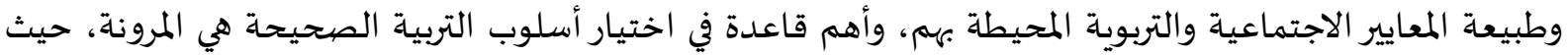
يجب أن يتحلى المبرون بالمرونة الكافية لاكتشاف أخطائهم وإصلاحها قبل فوات الأوان.

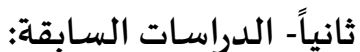

- - دراسة (Chandio-Ali-2019) هدفت الدراسة إلى معرفة مدى تأثير التنشئة الاجتماعية وعلاقتها القوية بتطور

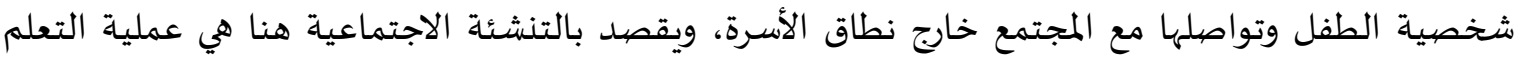

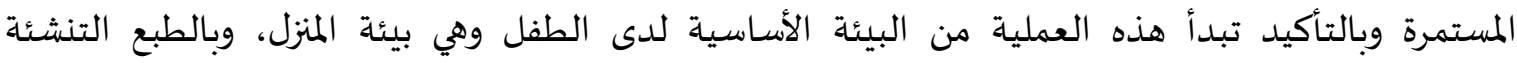

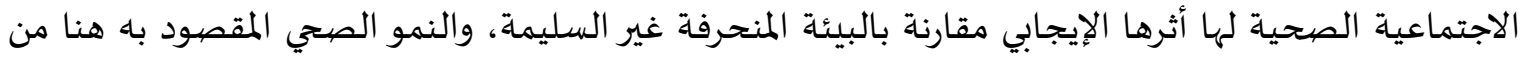

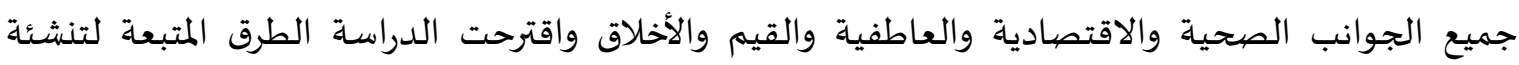
سليمة للطفل، واعتمدت الدراسة المنهج الوصفي النوعي وهي دراسة تجريبية للتحقق من تأثير العوامل الاجتماعية في تنشئة شخصية الطفل، وتم توزيع 238 استبانة وتحقق منها 200 وحافظ على اعتى الاستجابة 84.03 من مختلف شرائح المجتمع، واعتمدت الدراسة عدد من الفرضيات المتمثلة في الأولى: ماهي محددات واتئه

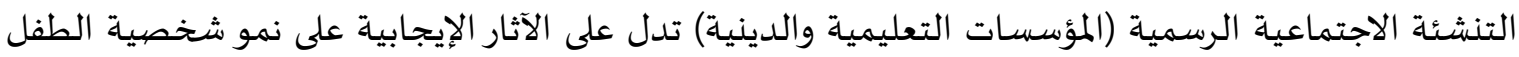

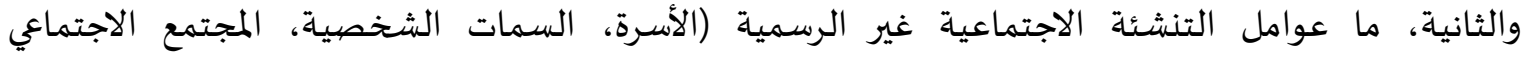

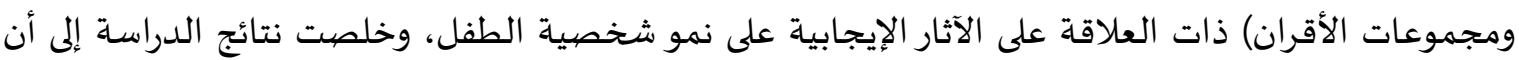
فشل استقرار الأسرة الاجتماعي والاقتصادي يؤدي إلى تراجع نمو الطفل المستقر مستقبلاً ووجود الأقران

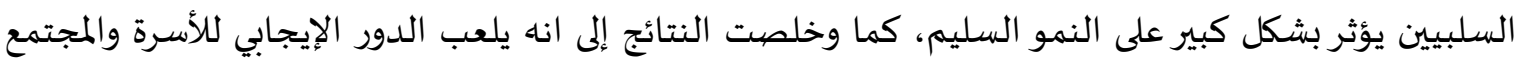
وظيفة كبيرة في تحفيز نمو شخصية مستقرة ومعتدلة للطفل. دراسة Jackie A Nelson, Theodore Dix, 2018)Justin K Scott ) هدفت الدراسة العلاقة الترابطية بين التكامل بين الوالدين وكفاءة أداء افراد الأسرة بمرور الوقت، اشتملت العينة على 710 أسرة لوالدين مرتبطين

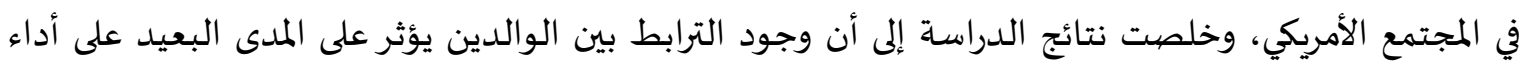

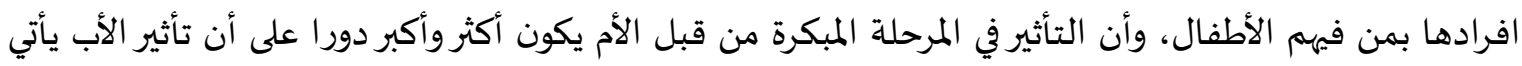
بالمرحلة المتوسطة بشكل أكبر. دراسة الظفيري، عبد الرحمن (2018) وهدفت الدراسة إلى التعرف على أهمية مهارات التربية الإيجابية التي

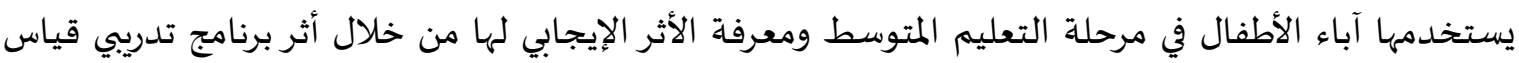

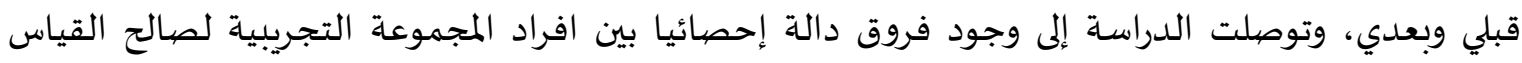

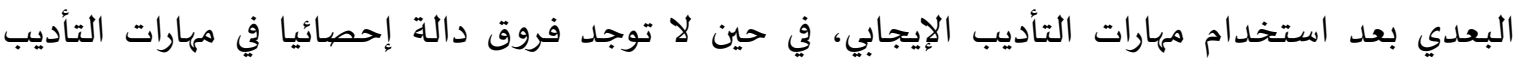
الإيجابي وفقا للمرحلة العمرية والصف الدراسي، واوصت الدراسة إلى تقديم الدعم للآباء في تربية ابنائهم في في في فيات

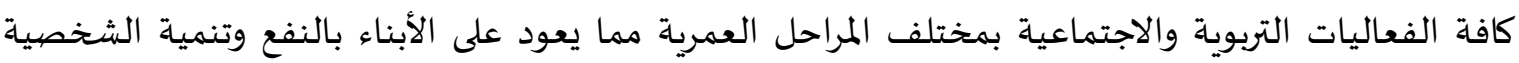


دراسة (and Marcia J. Carlson,2014Julia S. Goldberg) هدفت هذه الدراسة لمعرفة أثر الترابط الأسري ومستوى الإيجابية بين الوالدين ومستوى التفاهم على سلوك ابنائه، واستخدمت الدراسة أسلوب المقارنة بين

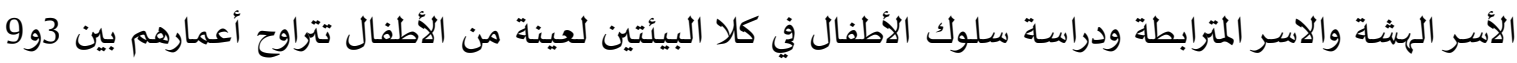

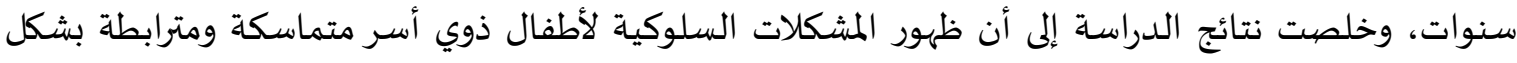

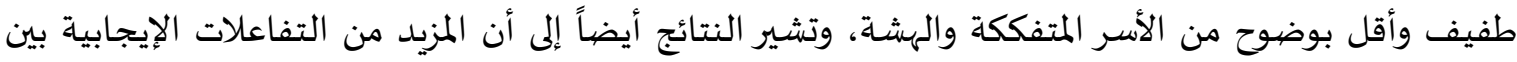
الزوجين تؤثر بشكل واضح على سلوك ابنائم بشكل إيجابي وهذ ما يتطلب من الواقع الاجتماعي للأسر. دراسة فوارس، هيفاء فياض (2013) هدفت الدراسة إلى الكشف عن الوظيفة التربوية للأسرة في الإسلام، والوقوف على ما شهدته هذه الوظيفة اليوم من تغيرات؛ حيث قامت الباحثة بتقسيم الدراسة إلى ثلاثة مباحث:

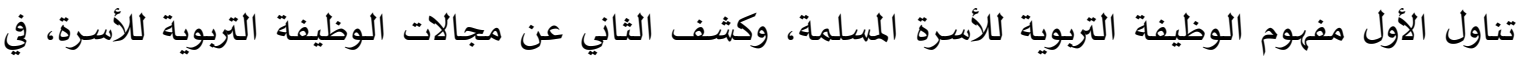

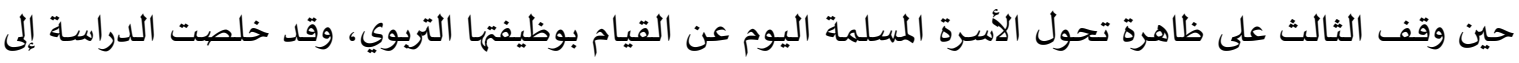

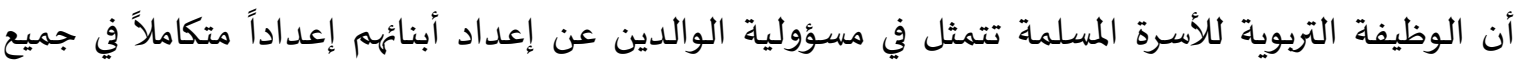

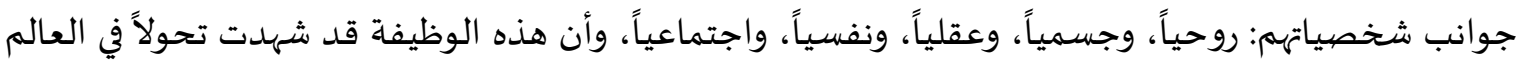

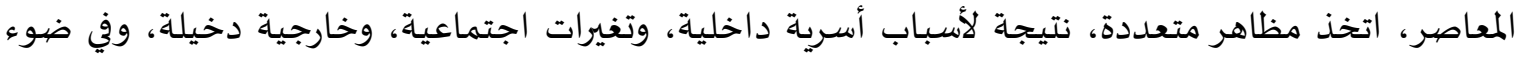
ذلك قدمت الدراسة مجموعة من الخطوات التي تسهم في عودة الأسرة للقيام بوظيفتها التربوية المناطة بها

دراسة Asonibare,F.B(2013 وهدفت إلى بيان مستوى الاتصال بين الآباء والأبناء وتبني المهارات الإيجابية في

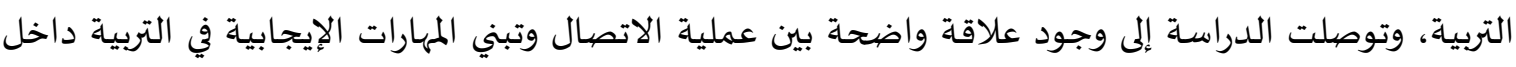

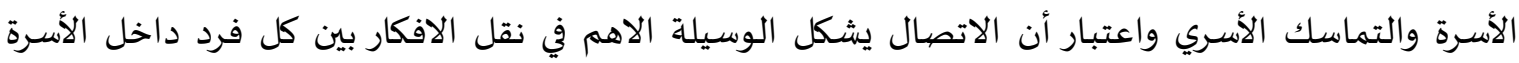

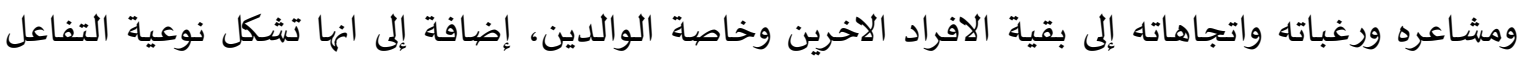
وتوجهه وجها إيجابية في حال كانت أساليب التواصل جيده ووجهه سلبية في حال كانت أساليب التواصل مشوشها داخل الأسرة. دراسة ( 2013, Rebecca Ryan, Amy Claessens, and Anna J. Markowitz) هدفت الدراسة إلى فحص دص العلاقة بين التماسك الأسري وأثره على تنشئة أطفال من الناحية السلوكية والناحية الإدراكية، واستخدمت

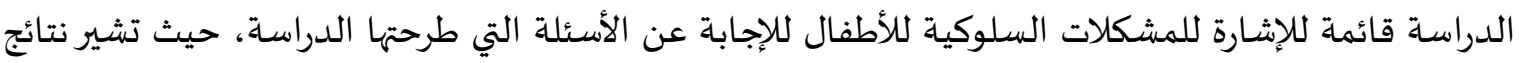

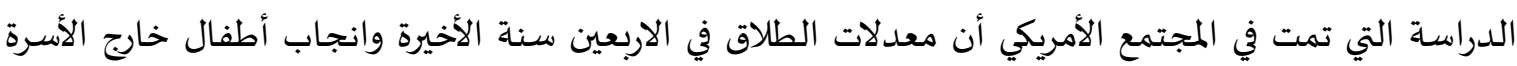

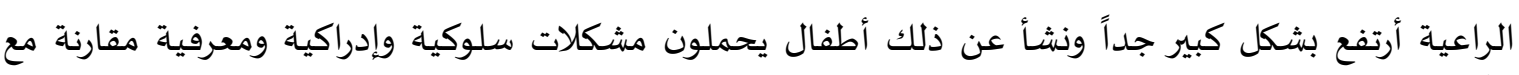

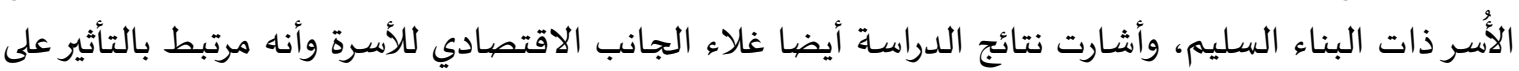

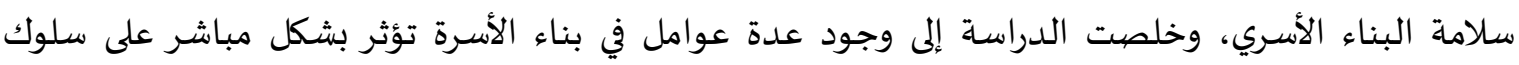

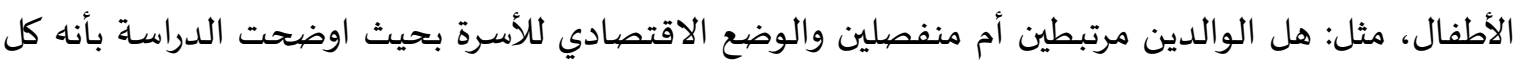

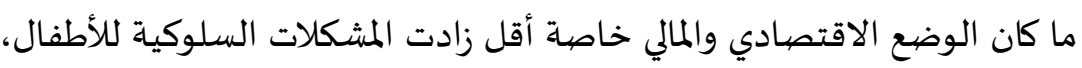
دراسة (Psicologia Aplicada2012). هدفت الدراسة إلى تحديد الاختلافات في سلوك الأطفال لدى ابوين منفصلين عن الأطفال الذين يعيشون مع ابويهم معا في المنزل وذلك بناءً على وجهة نظر كل من الآباء والمعلمين،

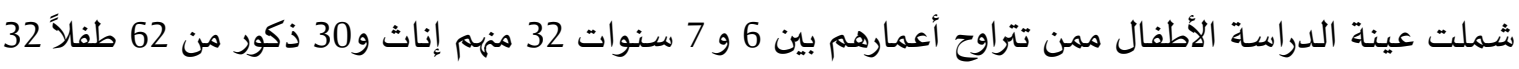

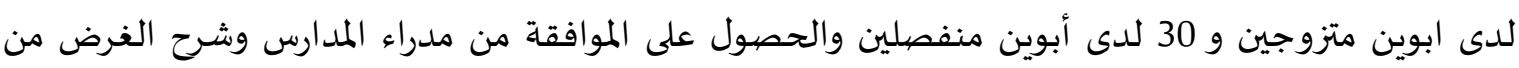

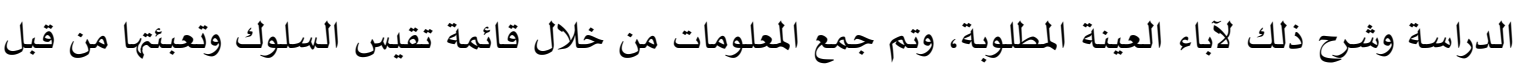


الآباء والمعلمين، وخلصت نتائج الدراسة إلى أن هناك فروق واضحة بين الفئتين من العينة وخاصة على الجانب

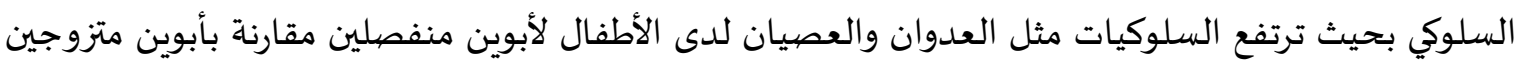

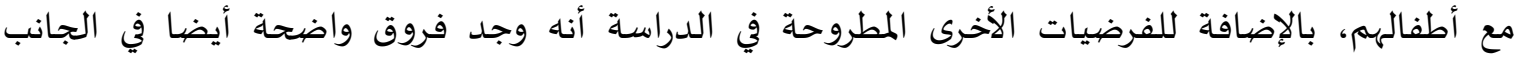

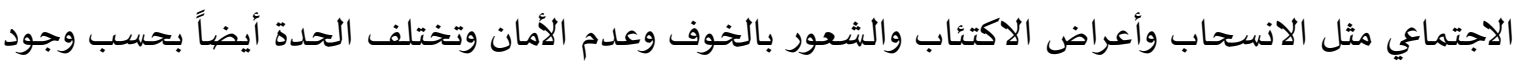

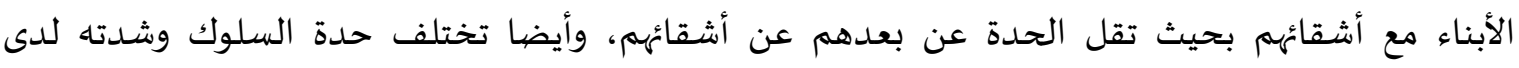

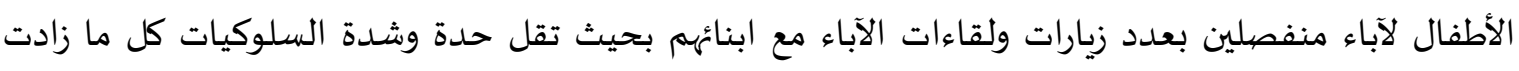

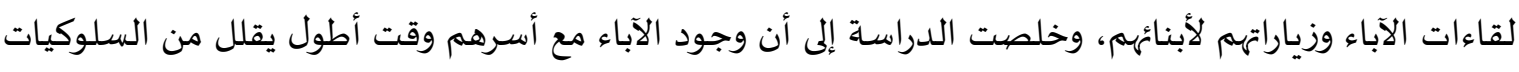
غير المقبولة لديهم وبالإضافة إلى وجودهم مع أشقائهم.

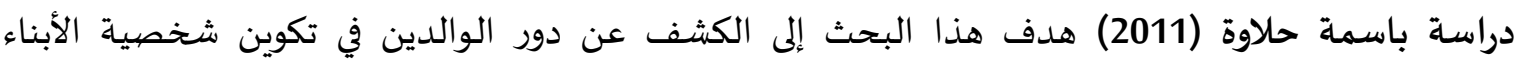

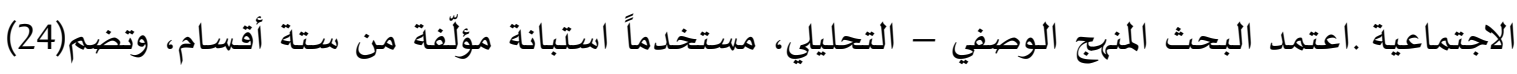

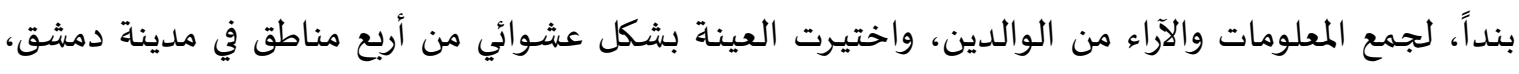

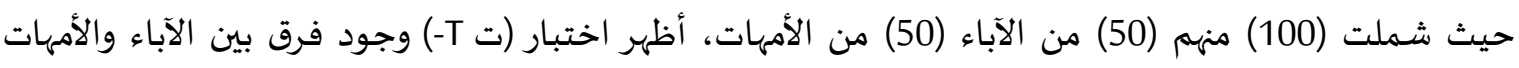

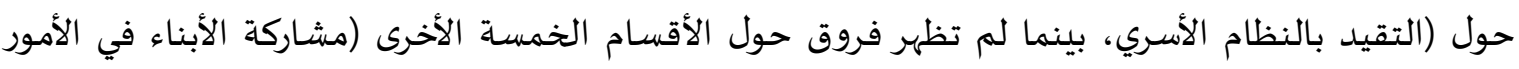

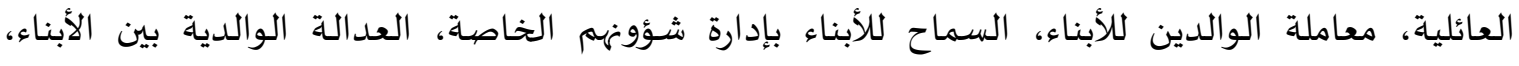

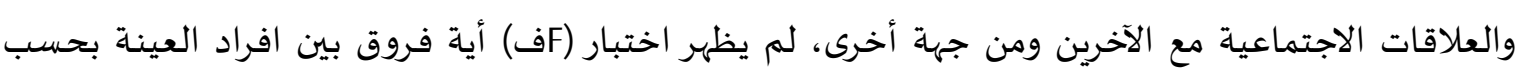

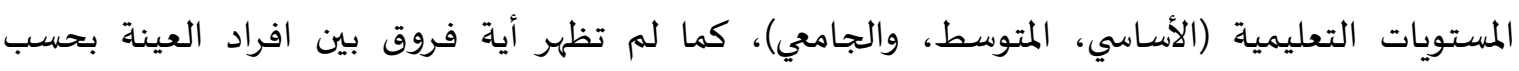

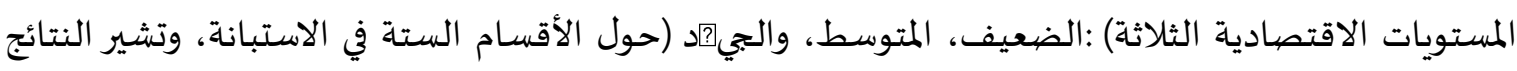

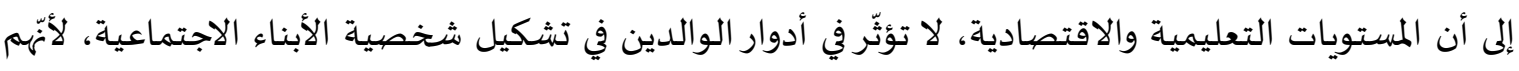
يعيشون ضمن منظومة واحدة من القيم والعادات الاجتماعية.

دراسة (Terry-Ann Craigie jeanneBrooks,2010Jane Waldfogel) هدفت الدراسة إلى المقارنة بين أطفال الأسر التي فيها العلاقات مضطربة بين الوالدين أو منفصلين والأسر التي لوالدين مرتبطين بعلاقات إيجابية،

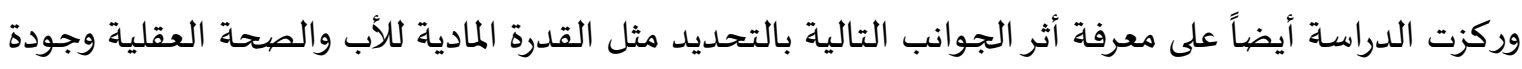

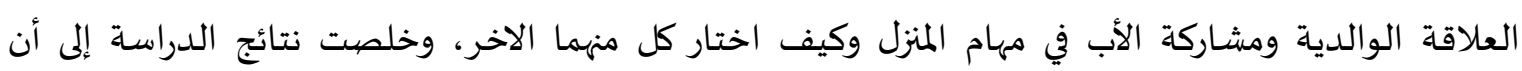

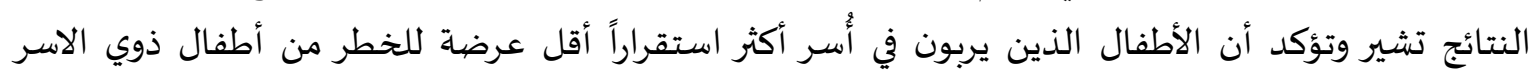

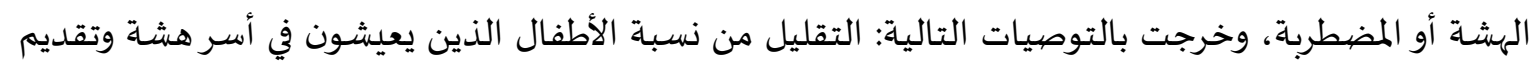

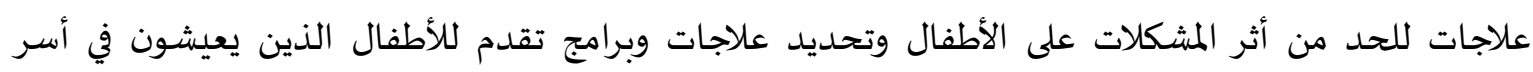

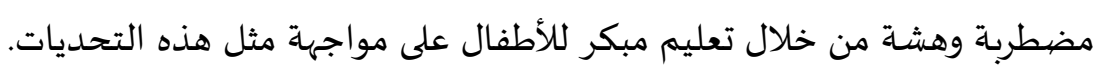

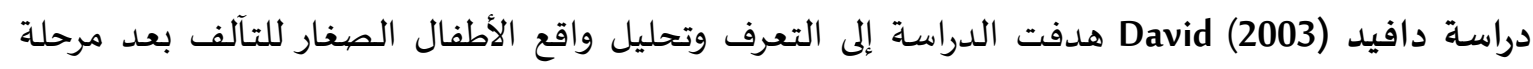

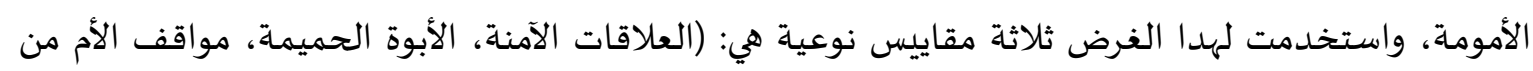

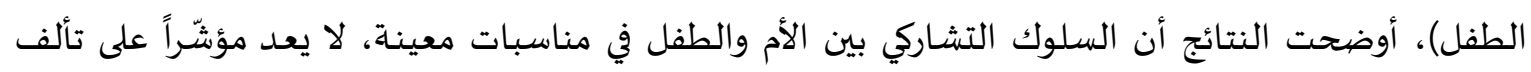

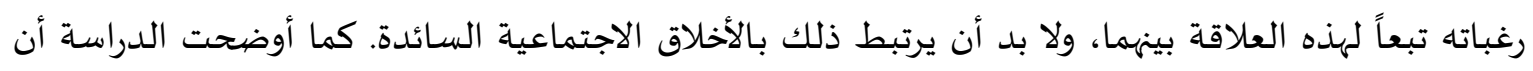

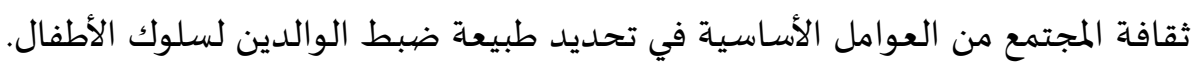
دراسة (CARLSON-CORCORAN,2001) وهدفت الدراسة إلى تبيان اختلاف البناء الأسري على سلوك

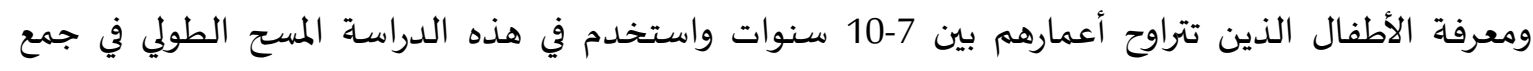

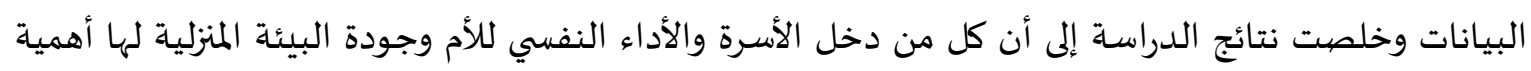


واضحة لسلوك الطفل، ومن جانب اخر تبين وجود أثرا واضحا في الجانب المادي للأسرة واداء الام النفسي على

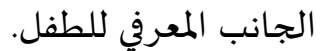

\section{تعليق على الدراسات السابقة.}

يلاحظ من الدراسات السابقة، العربية والأجنبية، أن بعضها ركّز على دور الوالدين في السلوك الشخصي

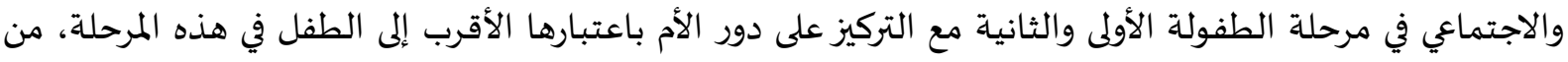
جها، وأهمية هذه المرحلة في وضع الملامح الأساسية لشخصية الطفل المستقبلية، من جهاة، كما في دراسة دافياة دافيد

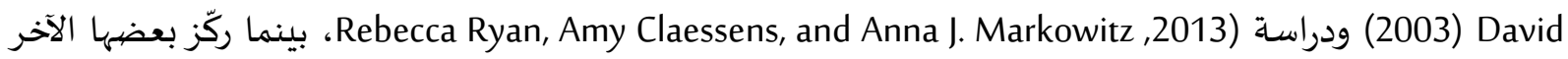
على أثر العناية الوالدية وتواجد الوالدين في المنزل في شخصية الطفل كما في دراستي دراسـ(Chandio-Ali-2019)

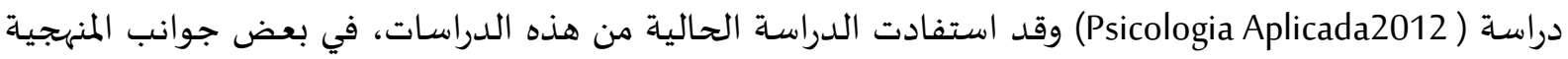

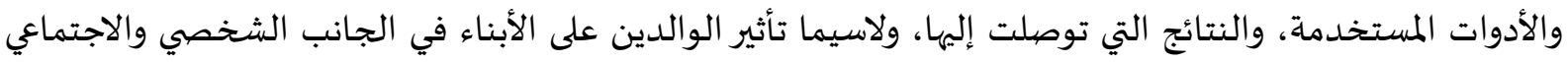

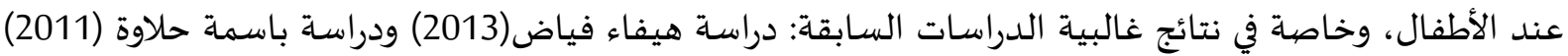
ودراسة Juckie A Nelson, Theodore Dix, 2018)Justin K Scott , ) اما الدراسة الحالية تختلف عن هذه الدراسات بشموليتها وتحديدا في ظروف أزمة اجتاحت العالم وظهور وباء عالمي اجبر الناس على البقاء في المنازل وفرض قيودا

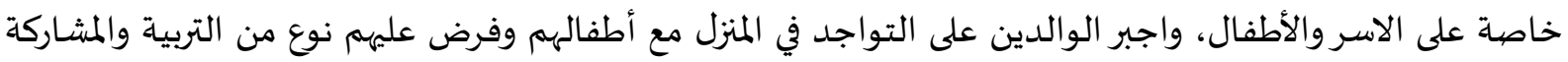
الفعلية في تربية ابنائهم.

3- منهجية البحث وإجراءاته.

منهجية البحث:

اتبع الباحثان المنهج الوصفي التحليلي في الدراسة الحالية، إذ يعد من أكثر مناهج البحث العلمية شيوعاً

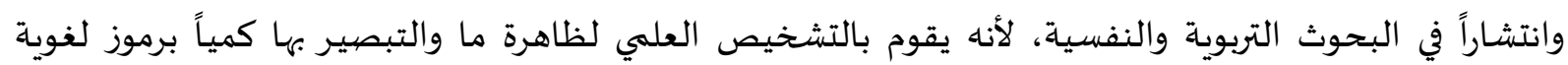
ورياضيية.

مجتمع البحث:

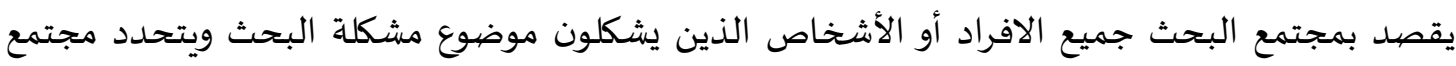
البحث الحالي بآباء وأمهات الأطفال القائمين على الاشراف والمتابعة وممن يتحملون المسؤولية في التربية والتنشئة

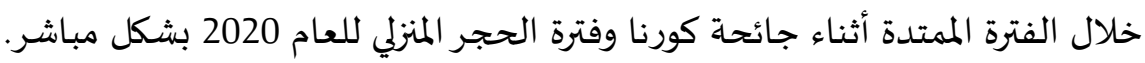

عينة البحث: يقصد بعينة البحث مجموعة جزئية من المجتمع الذي تجري عليه الدراسة اختارها الباحثان لوفق قواعد

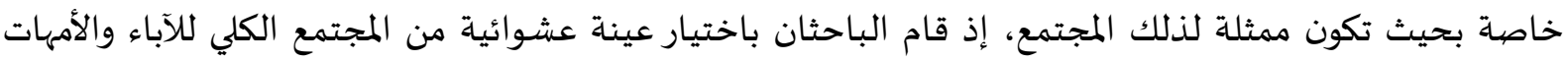

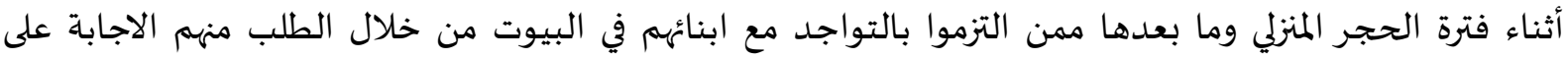

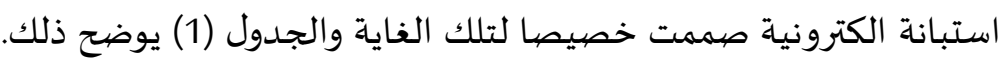


الجدول (1) عينة البحث الأساسية موزعة بالتساوي حسب المحافظة والدخل

\begin{tabular}{|c|c|c|c|c|}
\hline \multicolumn{2}{|c|}{ محافظات اخرى } & \multicolumn{2}{|c|}{ عمان } & المحافظة \\
\hline 499 فما دون & 500 فأكثر & 49 فما دون & 500 فأكثر & 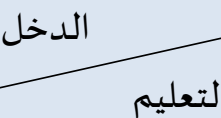 \\
\hline 64 & 48 & 60 & 54 & جامعي فأعلى \\
\hline 40 & 36 & 34 & 32 & أقل من جامعي \\
\hline 104 & 84 & 94 & 86 & المجموع \\
\hline
\end{tabular}

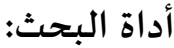

أ- الاستبيان الاستطلاعي: قام الباحثان بتوجياه سؤال مفتوح (استطلاعي) لمجموعة من اولياء الامور والخبراء وهم خارج عينة البحث الأساسية، وذلك لمعرفة اشكال وانماط السلوك الشخصي والاجتماعي لدى الأطفال 16 وما

ب- الاستبانة المغلقة: بعد استرجاع الباحثان لإجابات الآباء والخبراء حول السؤال الاستطلاعي المفتوح، قام الباحثان

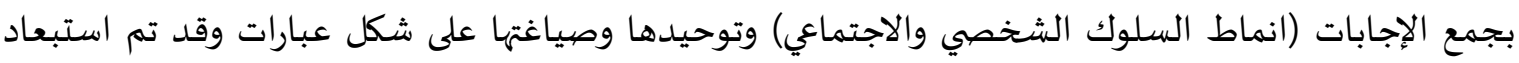

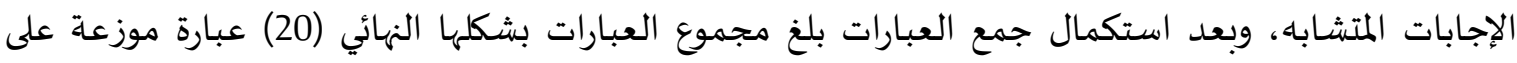

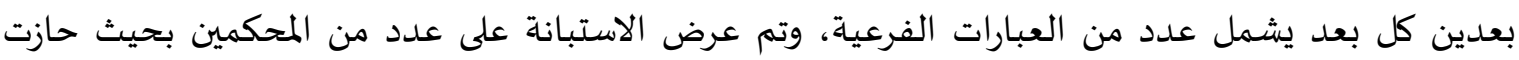

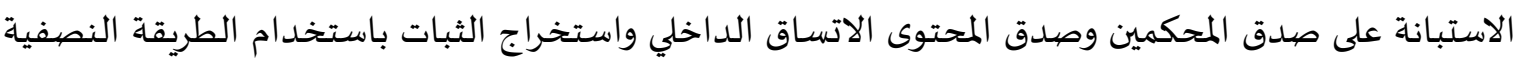

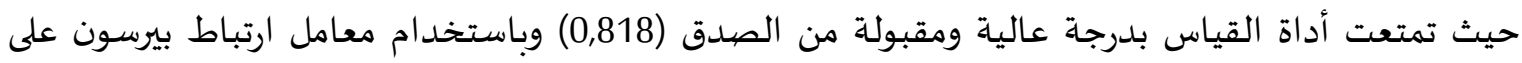

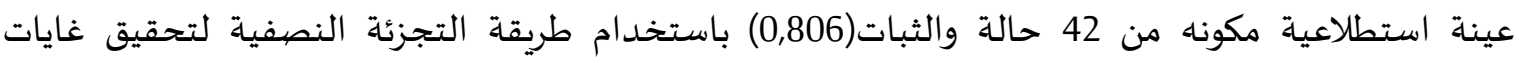

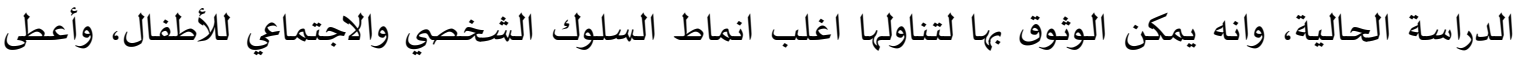

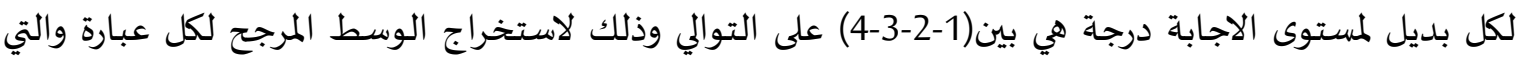

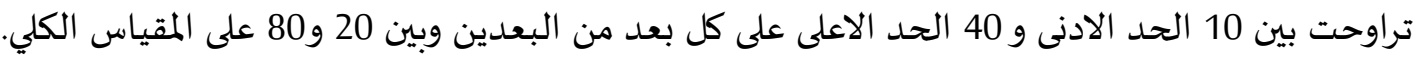

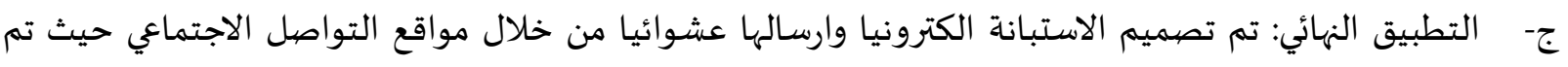

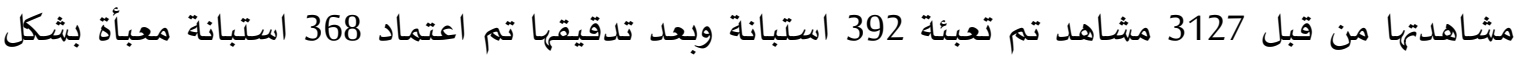

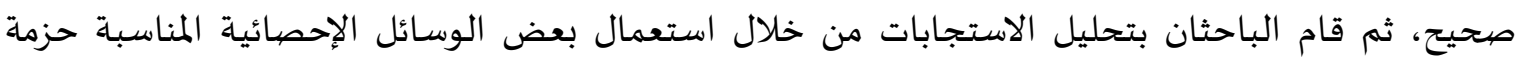

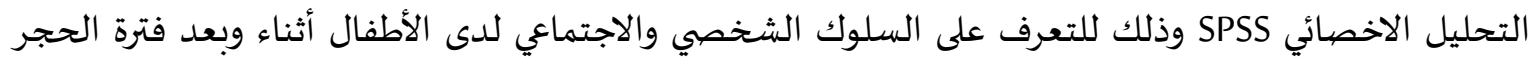
المنزلي. د- الوسائل الإحصائية: لمعالجة البيانات إحصائيا استخدم الباحثان التحليل الإحصائي باستخدام حزمة العلوم

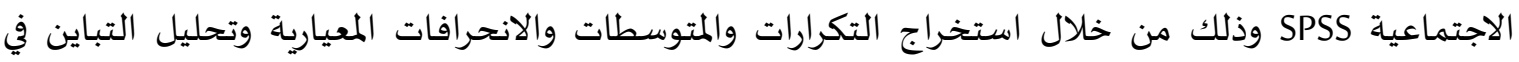

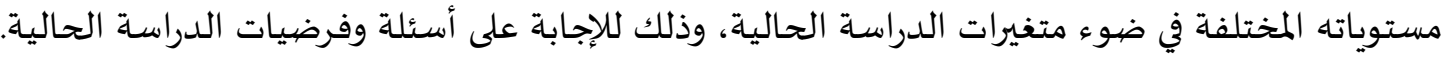


4- نتائج الدراسة ومناقشتها.

إجابة السؤال الرئيس: " ما أهم الآثار الإيجابية الناتجة عن تواجد الوالدين في المنزل أثناء وبعد جائحة كورونا في تحسن السلوك الشخصي والاجتماعي للأبناء ؟ ولإجابة على السؤال الرئيسي للدراسة والمتعلق بالآثار الإيجابية على كل من السلوك الشخصي والاجتماعي

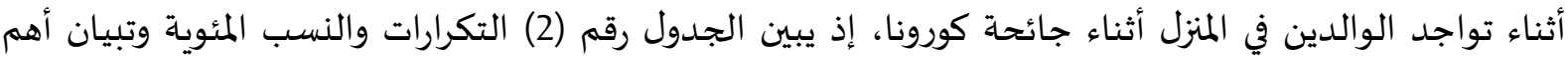
الآثار التي ظهرت في تحسن انماط السلوك الشخصي والتي كانت على النحو التالي:

$$
\text { جدول رقم (2) يبين التكرارات والنسب المئوية }
$$

محتوى مستويات التكرارات والنسب المئوية لترتيب عبارات بعد السلوك الشخصي.

\begin{tabular}{|c|c|c|c|c|c|}
\hline مقبولة & $\begin{array}{c}\text { متوسطة } \\
\%\end{array}$ & عالية \% & جد عالية & 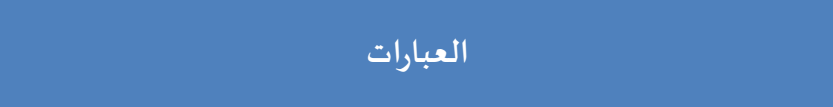 & $\hat{\imath}$ \\
\hline$\% 622$ & $\% 51188$ & $\% 2176$ & $\% 2282$ & تحسن لديه ترتيب وتنظيم الملابس في الخزانة. & .1 \\
\hline$\% 620$ & $\% 48178$ & $\% 2593$ & $\% 2177$ & تحسـن مشـاركته في أعمال المنزل العادية من تنظيف وتحضير. & .2 \\
\hline$\% 728$ & $\% 51186$ & $\% 2176$ & $\% 2178$ & تحسن لديه الاداء في إعداد وتناول الطعام. & .3 \\
\hline \%5 17 & \%53 195 & $\% 2178$ & $\% 2178$ & تحسن لديه المشـاركة في الجلسـات العائلية ومشاهدة لبرامج التلفزة. & .4 \\
\hline$\% 728$ & $\% 51185$ & $\% 1969$ & $\% 2386$ & تحسن لديه صور المشـاركة الإيجابية مع افراد العائلة. & .5 \\
\hline$\% 726$ & $\% 51189$ & $\% 2072$ & $\% 2281$ & تحسن لدي التفاعل والابتعاد عن العزلة. & .6 \\
\hline $\begin{array}{c}38 \\
\% 10\end{array}$ & $\% 51187$ & $\% 1968$ & $\% 2075$ & تحسـن لديه المشـاركة في الأحساديث والحوار والنقاش العائلي. & .7 \\
\hline$\% 932$ & $\% 51188$ & $\% 1972$ & $\% 2074$ & تحسن لديا الإنصـات والاستماع والتواصل مع الاخرين. & .8 \\
\hline$\% 934$ & \%51 187 & \%18 67 & $\% 2280$ & تحسن لدياه مستوى المشـاركة في اللعب والأنشطة الرياضية & .9 \\
\hline$\% 724$ & \%50 185 & $\% 2177$ & $\% 2282$ & أصبح أكثر مرحا وفرحا وسعادة من ذي قبل & .10 \\
\hline
\end{tabular}

حيث أظهر الجدول رقم (2) بأن سلوكيات الجانب الشخصا وسعة من في كما هي في العبارات التالية:

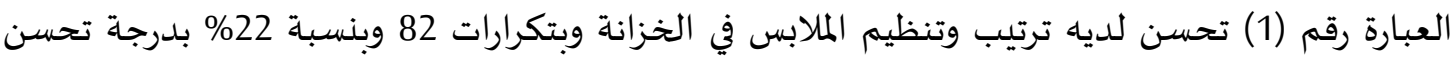

عالية جدا وتكرارات 76 وبنسبة 21\% بدرجة عالية وبتكرارات 178 وبنسبة 48\% بدرجة متوسطة وبتكرارات 20 وبنسبة 6\% بدرجة مقبولة.

العبارة رقم (2) تحسن مشاركته في أعمال المنزل من تنظيفه وتحضير وبتكرار 77 وبنسبة 21\% بدرجة تحسن عالية جدا وتكرار 93 وبنسبة 25\% بدرجة عالية وبتكرار 178 وبنسبة 48\% بدرجة متوسطة وبتكرار 20 وبنسبة 6\% بدرجة مقبولة.

العبارة رقم (3) تحسن لديه الاداء في إعداد وتناول الطعام وبتكرارات 78 وبنسبة 21\% بدرجة تحسن عالية جدا وتكرارات 76 وبنسب ة21\% بدرجة عالية وبتكرارات 186 وبنسبة 51\% بدرجة متوسطة وبتكرارات 28 وبنسبة 
العبارة رقم (4) تحسن لديه المشاركة في الجلسات العائلية ومشاهدة برامج التلفزة وبتكرارات 78 وبنسبة 21\% بدرجة تحسن عالية جدا وتكرارات 78 وبنسب ة21\% بدرجة عالية وبتكرارات 195 وبنسبة 53\% بدرجة

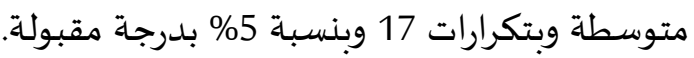

العبارة رقم (5) تحسن لديه صور المشاركة الإيجابية مع افراد العائلة وبتكرار 86 وبنسبة 23\% بدرجة تحسن عالية جدا وبتكرار 69 وبنسب ة19\% بدرجة عالية وبتكرار 185 وبنسبة 51\% بدرجة متوسطة وبتكرار 28 وبنسبة 7\% بدرجة مقبولة.

العبارة رقم (6) تحسن لدي التفاعل والابتعاد عن العزلة وبتكرارات 81 وبنسبة 22\% بدرجة تحسن عالية جدا وتكرارات 72 وبنسب 20\% بدرجة عالية وبتكرارات 189 وبنسبة 51\% بدرجة متوسطة وبتكرارات 26 وبنسبة 7\% بدرجة مقبولة.

العبارة رقم (7) تحسن لدياه المشاركة في الأحاديث والحواروالنقاش وبتكرار 75 وبنسبة 20\% بدرجة تحسن عالية جدا وتكرار 68 وبنسبة 19\% بدرجة عالية وبتكرار 187 وبنسبة 51\% بدرجة متوسطة وبتكرار 38 وبنسبة 10 بدرجة مقبولة. العبارة رقم (8) تحسن الإنصات والاستماع والتواصل مع الاخرين، وبتكرارات 74 وبنسبة 20\% بدرجة تحسن عالية جدا وتكرارات 72 وبنسبة 19\% بدرجة عالية وتكرار187 وبنسبة 51\% بدرجة متوسطة وبتكرارات 32 وبنسبة 9\% بدرجة مقبولة.

العبارة رقم (9) تحسن لديه مستوى المشاركة في اللعب والأنشطة رياضيه وبتكرارات 80 وبنسبة 22\% بدرجة تحسن عالية جدا وتكرارات 67 وبنسب ة18\% بدرجة عالية وبتكرارات 187 وبنسبة 51\% بدرجة متوسطة وبتكرارات 34 وبنسبة 9\% مقبولة.

العبارة رقم (10) أصبح أكثر مرحا وفرحا وسعادة من ذي قبل وبتكرارات 82 وبنسبة 22\% بدربة بدرة تحسن عالية جدا وتكرار 77 وبنسبة 21\% بدرجة عالية وبتكرار 185 وبنسبة 50\% بدرجة متوسطة وبتكرار 24 وبنسبة 7ه بدرجة مقبولة،

ويبين الجدول رقم (3) انماط السلوك الشخصي التي تعد أكثر تحسنا من بين السلوكيات الاخرى، حيث

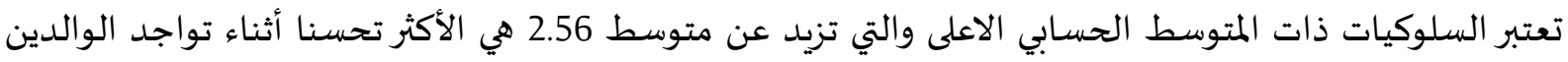
في المنزل وكما تظهر في الجدول التالي: جدول رقم (3) متوسطات عبارات السلوك الشخصي للأطفال مرتبة ترتيبا تنازليا حسب أثر التحسن نتيجة

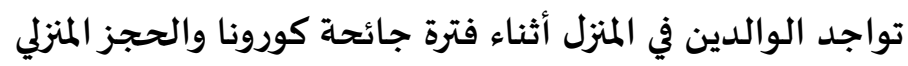

\begin{tabular}{|c|c|c|c|}
\hline 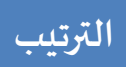 & المتوسط & 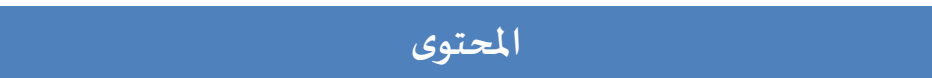 & رقم عبارة \\
\hline 1 & 2.59 & تحسن لديا ترتيب وتنظيم الملابس في الخزانة. & 4 \\
\hline 2 & 2.62 & تحسن مشـاركتاه في الأعمال المنزلية من تنظيف وإعداد وتحضير. & 1 \\
\hline 3 & 2.55 & تحسن لدياه الاداء في إعداد وتناول الطعام. & 7 \\
\hline 4 & 2.59 & تحسن المشـاركة في الجلسـات العائلية ومشاهدة البرامج التلفزيونية. & 3 \\
\hline 5 & 2,58 & تحسن لديا صور المشاركة الإيجابية مع افراد العائلة. & 5 \\
\hline 6 & 2,55 & تحسن لدي التفاعل والابتعاد عن العزلة. & 6 \\
\hline 7 & 2.49 & تحسن لديه المشاركة في الأحاديث والحواروالنقاش العائلي. & 10 \\
\hline 8 & 2.50 & تحسن لديه الإنصات ولا ستماع والتواصل مع الاخرين. & 9 \\
\hline
\end{tabular}




\begin{tabular}{|c|c|c|c|}
\hline 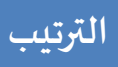 & المتوسط & 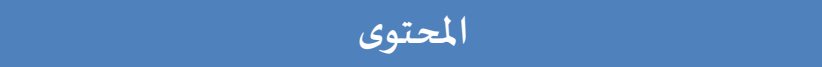 & رقم عبارة \\
\hline 9 & 2,52 & تحسن لدياه مستوى المشاركة في اللعب والأنشطة الرياضية & 8 \\
\hline \multirow[t]{2}{*}{10} & 2.59 & أصبح أكثر مرحا وفرح وسعادة من ذي قبل & 2 \\
\hline & 2.56 & المتوسط العام & \\
\hline
\end{tabular}

ويتضح من الجدول (3) أن غالبية عبارات السلوك الشخصي أظهرت تحسنا وكانت الأكثر تحسنا هي

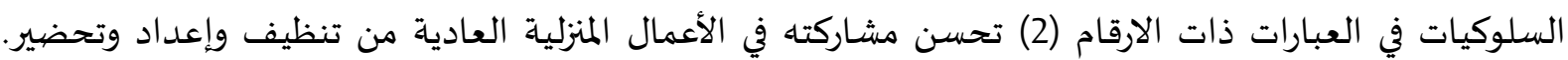
والرقم (10) أصبح أكثر مرحا وفرحا وسعادة من ذي قبل والرقم (4) تحسن لديه المشاركة في الجلسات العائلية

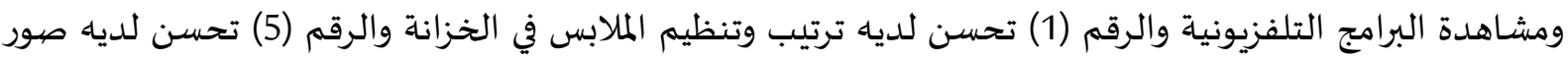

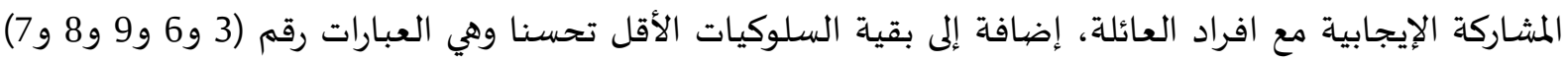
مرتبة ترتيبا تنازليا. ولأهمية إجابات الوالدين على انماط السلوك الشخصي ولإلهابابة على فرضيات الدراسة الأولى والثانية والثالثة وفي ضوء اختلافهم في مكان السكن ومستوى الدخل ومستوى التعليم فقد تم استخدام تحليل التباين الثلاثي وحساب المتوسطات الحسابية على النحو التالي: تم حساب المتوسطات الحسابية لمستوى العبارات في السلوك الشخصي بلئ بين المستجيبين من الآباء والأمهات

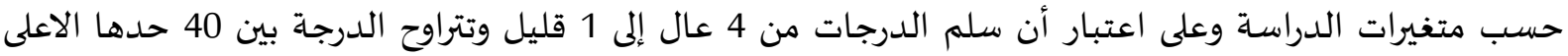
و10 كحدها الادنى حيث كانت قيم المتوسطات لافراد العينة على مقياس السلوك الشخصي على النحو الذي يظهر في الجدول رقم (4) - (4) الجدول رقم (4) المتوسطات الحسابية لافراد عينة الدراسة على عبارات أداة القياس بالبعد الأول الشخصي وفي ضوء متغيرات مكان السكن ومستوى الدخل ومستوى التعليم

\begin{tabular}{|c|c|c|c|c|}
\hline \multicolumn{2}{|c|}{ محافظات اخرى } & \multicolumn{2}{|c|}{ عمان } & المحافظة \\
\hline 499 فما دون & 500 فأكثر & 499 فما دون & 500 فأكثر & \\
\hline 28.3 & 28.1 & 27.8 & 28.3 & جامعي فأعلى \\
\hline 27.9 & 27.8 & 27.6 & 27.9 & أقل من جامعي \\
\hline
\end{tabular}

يلاحظ من جدول رقم (4) بأن المتوسطات الحسابية متقاربه في قيمها في معظم حالاتها ولمعرفة دلالة الفروق بين تلك المتوسطات اجري تحليل التباين الثلاثي ذو التصميم العاملي 2*2*2 ويظهر الجدول رقم (5) خلاصية تحليل النتائج. الجدول رقم (5) تحليل التباين الثلاثي للقياس الكلي للسلوك الشخصي للأطفال في ضوء متغيرات مكان السكن ومستوى الدخل ومستوى التعليم

\begin{tabular}{|c|c|c|c|c|c|}
\hline مستوى الدلالة & ف المحسوبة & متوسط المربعات & الحرجة & المربعات & مصدر التباين \\
\hline 0.612 & 0.16 & 0.88 & 1 & 0.88 & مكان السكن \\
\hline 0.112 & 1.66 & 8.11 & 1 & 8.11 & ومستوى الدخل \\
\hline 0.488 & 0.26 & 1.78 & 1 & 1.78 & مستوى التعليم \\
\hline
\end{tabular}




\begin{tabular}{|c|c|c|c|c|c|}
\hline مستوى الدلالة & ف المحسوبة & المربعات & الحرية & المربعات & 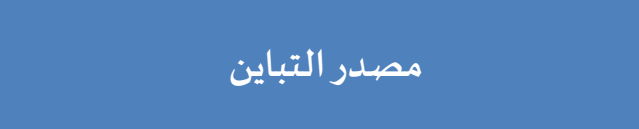 \\
\hline 0.886 & 0.02 & 0.36 & 1 & 0.36 & مكان السكن ومستوى الدخل \\
\hline 0.298 & 0.88 & 4.22 & 1 & 4.22 & مكان السكن ومستوى التعليم \\
\hline 0.078 & 2.88 & 42.12 & 1 & 42.12 & مستوى الدخل ومستوى التعليم \\
\hline 0.194 & 2.01 & 9.23 & 1 & 9.23 & مكان السكن ومستوى الخبرة ومستوى التعليم \\
\hline
\end{tabular}

وتدل النتائج الظاهرة في الجدول رقم (5) انه لم تظهر اية فروق المات ذات دات دلالة إحصائية عند مستوى الدلالة (0,05) يمكن تعود إلى أي من متغيرات الدراسة (مكان السكن ومستوى الدخل ومستوى التعليم)، بالإضافة إلى عدم إنداف

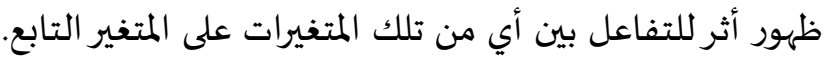
اما ما يخص البعد الثاني إذ يبين الجدول رقم (6) التكرارات والمتوسطات الحسابية وتبيان أهم الآثار التي ظهرت في تحسن انماط السلوك الاجتماعي والتي كانت على النحو التالي:

$$
\text { جدول رقم (6) التكرارات والنسب المئوية }
$$

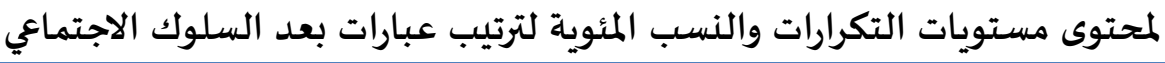

\begin{tabular}{|c|c|c|c|c|c|}
\hline مقبولة \% & متوسطة \% & عالية \% & درجة عالية جداً \% & المحتوى التكرارات والنسبة & $\hat{\hat{c}}$ \\
\hline$\% 828$ & \%51 187 & $\% 2179$ & $\% 2074$ & اوقات الجلوس مع الأسرة مثمرة وإيجابية & 1 \\
\hline$\% 932$ & \%49 182 & $\% 2177$ & $\% 2177$ & اصبح افضل في طريقة الحواروالنقاش مع اسرته & 2 \\
\hline \%9 34 & \%51 187 & \%19 71 & $\% 2176$ & يقضي اوقات جيدة في اللعب بالهادف & 3 \\
\hline$\% 726$ & \%52 191 & $\% 2179$ & \%19 72 & اصبح منظما أكثر في حركته وأداء مهماته & 4 \\
\hline$\% 727$ & \%53 197 & \%1972 & \%19 72 & انخفض معدل السلوك العدواني اتجاه العائلة & 5 \\
\hline$\% 828$ & \%48 178 & \%2384 & $\% 2178$ & يتفاعل الطفل عاطفيا مع والديه بالشكل المناسب & 6 \\
\hline$\% 725$ & \%51 188 & $\% 2178$ & \%21 77 & اصبح الطفل يدرك دوره الاجتماعي في الممزل & 7 \\
\hline \%10 38 & $\% 51186$ & $\% 1970$ & $\% 2074$ & يتفهم الطفل رفض الوالدين في بعض المواقف & 8 \\
\hline$\% 1035$ & \%51 187 & \%20 73 & \%20 73 & يحترم الطفل أوقات الجلوس على الطعام & 9 \\
\hline$\% 935$ & \%48 178 & $\% 2282$ & $\% 2073$ & يطلب الطفل حاجياته بالشكل المناسب & 10 \\
\hline
\end{tabular}

حيث أظهر الجدول رقم (6) بأن سلوكيات الجانب الاجتماعي كما هي في العبارات التالية:

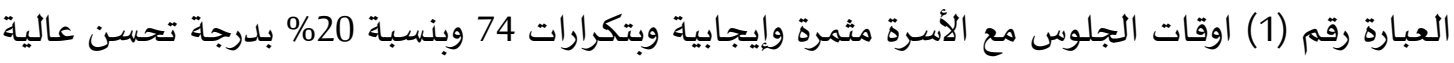

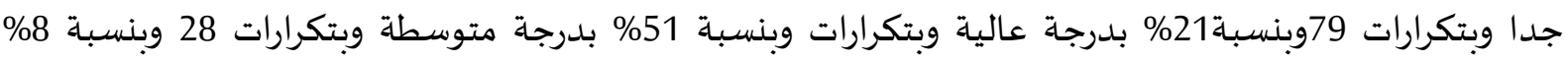
بدرجة مقبولة. العبارة رقم (2) أصبح أفضل في طريقة الحوار والنقاش وبتكرارات 77 وبنسبة 21\% بدرجة تحسن عالية

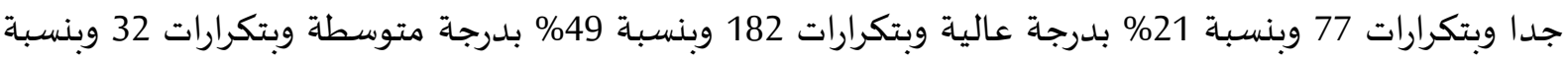
9 ب بدرجة مقبولة. العبارة رقم (3) يقضي اوقات جيدة في اللعب بالهادف وبتكرارات 76 وبنسب ة21\% بدرجة تحسن عالية جدا وبتكرارات 71 وبنسب ة19\% بدرجة عالية وبتك رارات187 وبنسبة 51\% بدرجة متدة متوسطة وبتكرارات 34 وبنسبة 9 9 بدرجة مقبولة. 
العبارة رقم (4) أصبح منظما أكثر في حركته وأداء مهماته وبتكرارات 72 وبنسبة 22\% بدرجة تحسن عالية جدا وبتكرارات 76 وبنسب ة21\% بدرجة عالية وبتك رارات188 وبنسبة 51\% بدرجة متوسطة وبتكرارات 22 وبنسبة

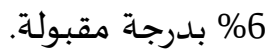

العبارة رقم (5) انخفض معدل السلوك العدواني اتجاه العائلة وبتكرارات 72 وبنسبة 19\% بدرجة تحسن عالية جدا وبتكرارات 72 وبنسبة 19\% بدرجة عالية وبتكرارات 197 وبنسبة 53\% بدرجة متوسطة وبتكرارات 27 وبنسبة 7\% بدرجة مقبولة.

العبارة رقم (6) يتفاعل الطفل عاطفيا وو الديه بالشكل المناسب وبتكرارات 78 وبنسبة 21\% بدورة بدرجة تحسن عالية جدا وبتكرارات 84 وبنسبة 23\% بدرجة عالية وبتكرارات 178 وبنسبة 48\% بدرجة متوسطة وبتكرارات 28 وبنسبة 8\% بدرجة مقبولة.

العبارة رقم (7) أصبح الطفل يدرك دوره الاجتماعي في المنزل وبتكرارات 77 وبنسبة 21\% بدورة بدرجة تحسن عالية جدا وبتكرارات 78 وبنسب ة21\% بدرجة عالية وبتك رارات188 وبنسبة 51\% بدرجة متوسطة وبتكرارات 25 وبنسبة 7\% بدرجة مقبولة.

العبارة رقم (8) يتفهم الطفل رفض الوالدين في بعض المواقف وبتكرارات 74 وبنسبة 20\% بدرجة تحسن

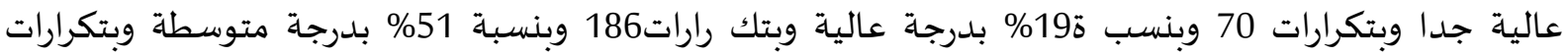
38 3بنسبة 10\% بدرجة مقبولة،

العبارة رقم (9) يحترم الطفل أوقات الجلوس على الطعام وبتكرارات 73 وبنسبة 20\% بدرجة تحسن عالية جدا وتكرارات 73 وبنسب 20\% بدرجة عالية وبتك رارات187 وبنسبة 51\% بدرجة متوسطة وبتكرارات 35 وبنسبة 10 بدرجة مقبولة،

العبارة رقم (10) يطلب الطفل حاجياته بالشكل المناسب وبتكرارات 73 وبنسبة 20\% بدرجة تحسن عالية جدا وبتكرارات 82 وبنسب ة22\% بدرجة عالية وبتكرارات 178 وبنسبة 48\% بدرجة متوسطة وبتكرارات 35 وبنسبة

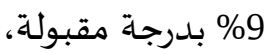

ويبين الجدول رقم (7) انماط السلوك الاجتماعي التي تعد أكثر تحسنا من بين السلوكيات الاخرى، حيث تعتبر السلوكيات ذات المتوسط الحسابي الاعلى والتي تزيد عن متوسط 2.53 هي الأكثر تحسنا أثناء تواجد الوالين الوالدين في المنزل وكما تظهر في الجدول التالي:

جدول رقم (7) متوسطات عبارات السلوك الاجتماعي للأطفال مرتبة ترتيبا تنازليا

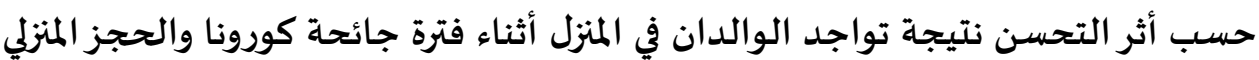

\begin{tabular}{|c|c|c|c|}
\hline 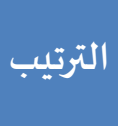 & المتوسط & 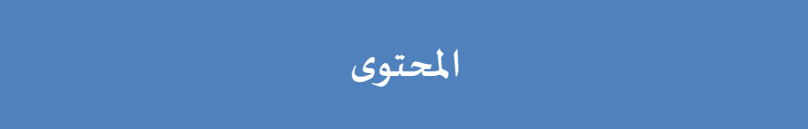 & رقبم \\
\hline 1 & 2.54 & اوقات الجلوس مع الأسرة مثمرة وإيجابية & 4 \\
\hline 2 & 2.55 & أصبيح أفضل في طريقة الحواروالنقاش مع اسرته & 3 \\
\hline 3 & 2.51 & يقضي اوقاتا جيدة في اللعب الهادف & 7 \\
\hline 4 & 2.53 & اصبح منظما أكثر في حركته وأداء مهماته & 5 \\
\hline 5 & 2.51 & انخفض معدل السلوك العدواني اتجاه اخوته ووالديه & 8 \\
\hline 6 & 2.58 & يتفاعل الطفل عاطفيا مع والدياه واخوته بالشكل المناسب & 1 \\
\hline 7 & 2.57 & اصبح الطفل يدرك دوره الاجتماعي في المنزل & 2 \\
\hline
\end{tabular}




\begin{tabular}{|c|c|c|c|}
\hline 8 & 2.49 & يتفهم الطفل رفض الوالدين في بعض المواقف & 10 \\
\hline 9 & 2.50 & يحترم الطفل أوقات الجلوس على الطعام & 9 \\
\hline 10 & 2.52 & يطلب الطفل حاجياته بالشكل المناسب & 6 \\
\hline & 2.53 & المتوسط العام & \\
\hline
\end{tabular}

ويتضح من الجدول (7) أن غالبية عبارات السلوك الاجتماعي أظهرت تحسنا وكانت الأكثر تحسنا هي

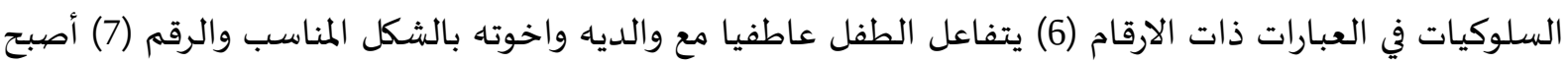
الطفل يدرك دوره الاجتماعي في المنزل والرقم (2) أصبح أفضل في طريقة الحواروالنقاش مع اسرتهاته والرقم (1) اوقات الهات

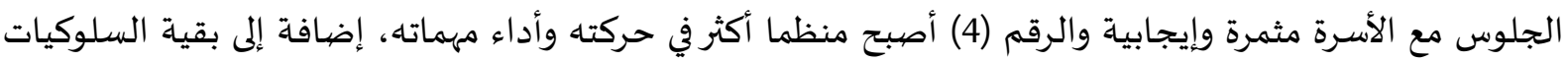
الأقل تحسنا وهي العبارات رقم(10و3و5و9و8) مرتبة ترتيبا تنازليا.

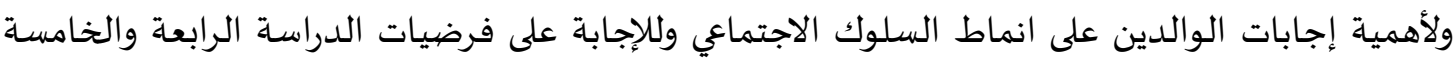
والسادسة وفي ضوء اختلافهم في مكان السكن ومستوى الدخل ومستوى التعليم، فقد تم استخدام تحليل التباين الثلاثي وحساب المتوسطات الحسابية على النحو التالي: تم حساب المتوسطات الحسابية لمستوى العبارات في السلوك الاجتماعي بين المستجيبين من الآباء والأمهات

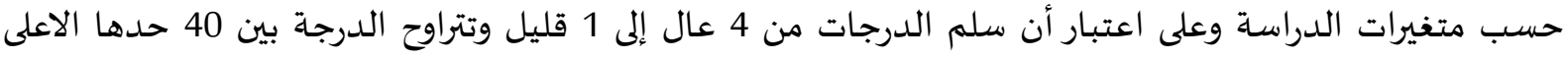

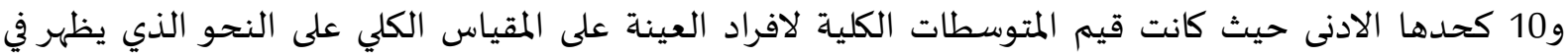

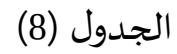

$$
\text { الجدول رقم (8) المتوسطات الحسابية لافراد عينة الدراسـة على عبارات }
$$

أداة القياس بالبعد الأول الاجتماعي في ضوء متغيرات مكان السكن ومستوى الدخل ومستوى التعليم

\begin{tabular}{|c|c|c|c|c|}
\hline \multicolumn{2}{|c|}{ محافظات اخرى } & \multicolumn{2}{|c|}{ عمان } & المحافظة \\
\hline 499 فما دون & 500 فأكثر & 499 فما دون & 500 فأكثر & \\
\hline 27.3 & 27.1 & 25.8 & 26.3 & جامعي فأعلى \\
\hline 25.9 & 26.8 & 25.6 & 26.9 & أقل من جامسي \\
\hline
\end{tabular}

يلاحظ من جدول رقم (8) بأن المتوسطات الحسابية متقاربه في قيمها في معظم حالاتها ولمعرفة دلالة الفروق بين تلك المتوسطات اجري تحليل التباين الثلاثي ذو التصميم العاملي 2*2*2 ويظهر الجدول رقم (9) خلاصية تحليل النتائج 


$$
\text { الجدول رقم (9) تحليل التباين الثلاثي }
$$

للقياس الكلي السلوك الاجتماعي للأطفال في ضوء متغيرات مكان السكن ومستوى الدخل ومستوى التعليم

\begin{tabular}{|c|c|c|c|c|c|}
\hline مستوى الدلالة & فلمسبوبة فلمبة & متوسط المربعات & الحرية & مجموع المربعات & مصدر التباين \\
\hline 0.512 & 0.14 & 0.81 & 1 & 0.78 & 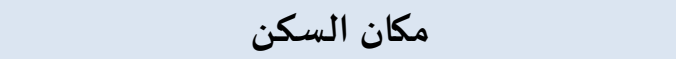 \\
\hline 0.089 & 1.02 & 7.44 & 1 & 6.12 & 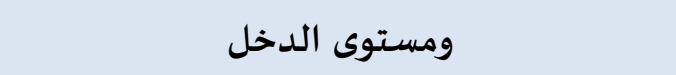 \\
\hline 0.433 & 0.34 & 1.13 & 1 & 1.22 & مستوى التعليم \\
\hline 0.644 & 0.03 & 0.41 & 1 & 0.43 & مكان السكن ومستوى الدخل \\
\hline 0.231 & 0.78 & 3.98 & 1 & 3.77 & مكان السكن ومستوى التعليم \\
\hline 0.076 & 2.23 & 36.98 & 1 & 32.78 & مستوى الدخل ومستوى التعليم \\
\hline 0.146 & 1.97 & 7.99 & 1 & 8.98 & مكان السكن ومستوى الخبرة ومستوى التعليم \\
\hline
\end{tabular}

وتدل النتائج الظاهرة في الجدول رقم (9) انه لم تظهر اية فروق ذات دلالة إحصائية عند مستوى الدلالة (0,05) يمكن ارجاعها إلى أي من متغيرات الدراسة (مكان السكن ومستوى الدخل ومستوى التعليم)، بالإضافة إلى عدم ظهور أثر للتفاعل بين أي من تلك المتغيرات على المن منير المتير التابع.

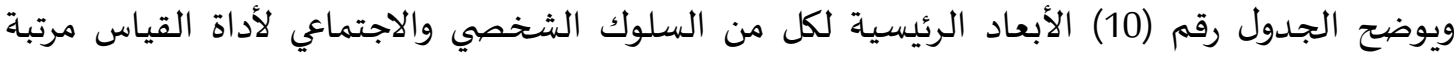
ترتيبا تنازليا حسب الافضلية في التحسن بالنسبة للأطفال وتأثير تواجد الوالدين في المنزل الجدول رقم (10) - (10)

الأبعاد الرئيسية لأداة القياس للسلوك الشخصي والاجتماعي مرتبة ترتيبا تنازليا حسب اهميتها

\begin{tabular}{|c|c|c|c|}
\hline المتوسط & البعد البد & رقم البعد & الترتيب \\
\hline 2.56 & بعد السلوك الشخصي & 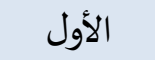 & .1 \\
\hline 2.53 & بعد السلوك الاجتماعي & الثاني & .2 \\
\hline
\end{tabular}

يتضح من الجدول رقم (10) أن البعد الأول السلوك الشخصي وبمتوسط عام (2.56) أكثر تحسنا من البعد الاجتماعي وبمتوسط (2.53) وبدرجة بسيطة.

مناقشـة النتائج: هدف البحث الحالي إلى الكشف عن أهمية وجود الوالدين في المنزل أثناء جائحة كورونا باعتبارهم

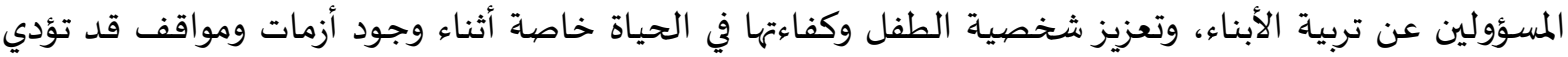

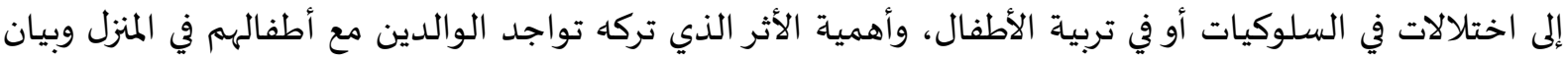

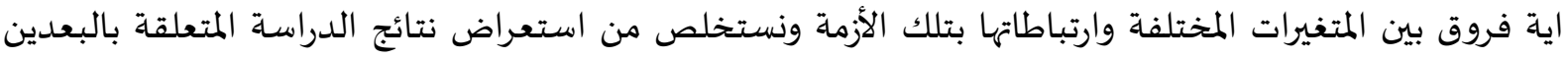
الشخصي والاجتماعي ما يلي: لقد ظهر تحسنا على العديد من سلوكيات الأطفال وبأثر إيجابي نتيجة تواجد الوالدين في المنزل أثناء

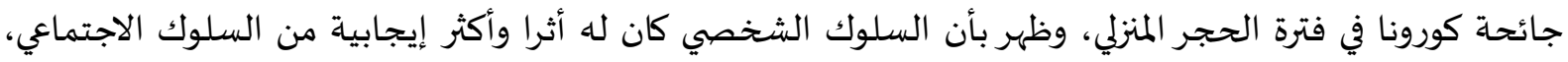

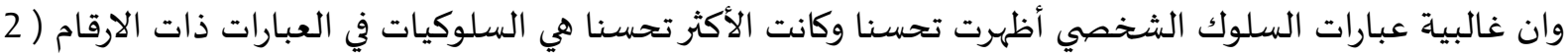

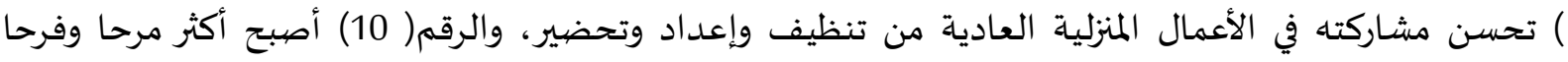
وسعادة من ذي قبل والرقم (4) تحسن لديه المشاركة في الجلسات العائلية ومشاهدة البرامج التلفزيونية والرقم (1) 
تحسن لدياء ترتيب وتنظيم الملابس في الخزانة والرقم (5) تحسن لدياه صور المشاركة الإيجابية مع افراد العائلة، وان

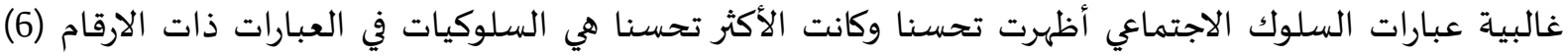
يتفاعل الطفل عاطفيا مع والديه واخوته بالشكل المناسب والرقم(7) اصبح الطفل يدرك دوره الاجتماعي في المنزل والرقم (2) اصبح افضل في طريقة الحوار والنقاش مع اسرته والرقم (1) اوقات الجلوس مع الأسرة مثمرة وإيجابية

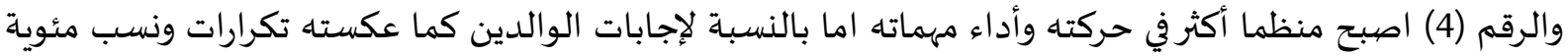
في الجداول المبينة في الدراسة الحالية، فقد ظهر أن مجموع الإجابات والتكرارات والنسب المئوية كانت في اتجاهية التهاه الأثر الإيجابي بدءا من المتوسط إلى العالي، مما اعطى انطباعا أثناء قراءة الجداول ونسبها بأن تواجد الوالدين في المنزل أثناء جائحة كورونا كان له أثر إيجابي في تحسن السلوك الشخصي والاجتماعي لدى الأطفال. وقد خلصت نتائج هذه الدراسة إلى انه لا توجد فروق ذات دلالة عند مستوى(0,05) بين استجابات افراد عينة الدراسة من الآباء والأمهات على البعدين السلوك الشخصي والسوك الاجتماعي، حيث يرى الباحثان أن مسالة عدم وجود فروق قد يعود إلى طبيعة تكوين الأسرة الأردنية في تربية الأبناء بانها متقاربة في كافة محافظات المملكة، وانها أسرة تنشئه أبناءها على الحب والاحترام وانها اسر دينية واجتماعية وتربوية وثقافية ذات منهج متقارب في التربية والتنشئة، إضافة إلى المتغيرات الخاصة بالدراسة والتفاعل فيما بينها وذلك لتبني افراد العينة من الآباء والأمهات فلسفة واحدة واتساق بين الاسر الأردنية في مختلف المحافظات كما يراها الباحث والكثير من الخبراء التربويين وقد اتضح ذلك في نتائج دراسة كل من دافيد David (2003) و (2013, Rebecca Ryan, Amy Claessens, and Anna J. Markowitz. بالتأكيد على أهمية التفاعل مع النسق الأسري في المنزل. كذلك فقد لوحظ من إجابات الوالدين أن الحجر المنزلي والتزام الأبناء وتواجدهم في المنزل دفع الأبناء

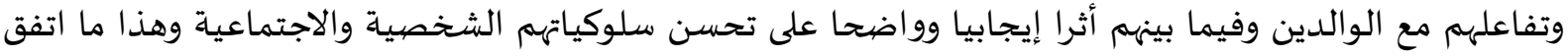

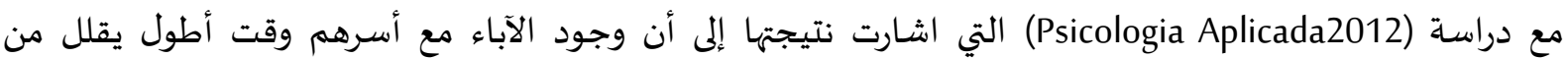

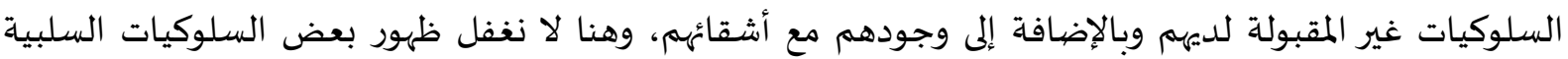

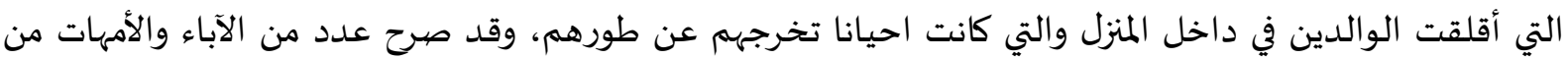

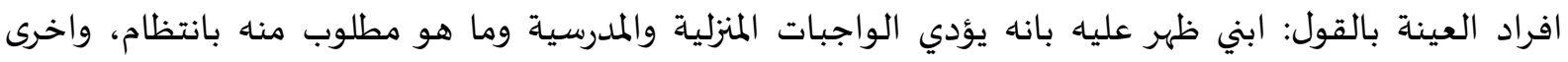

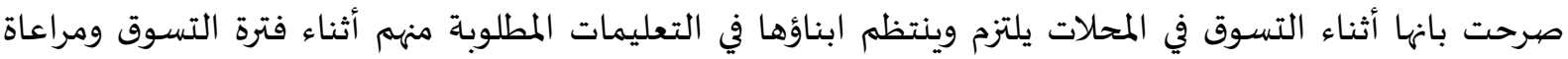

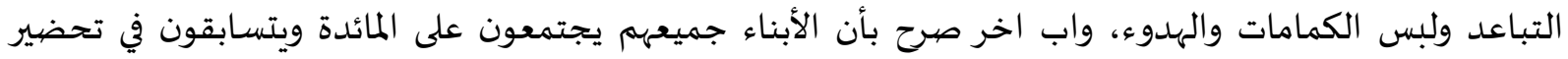

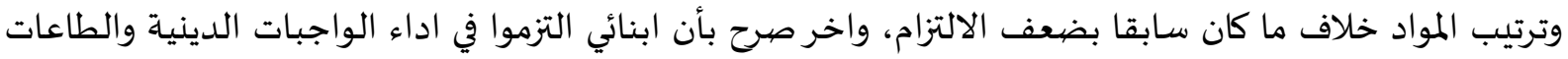

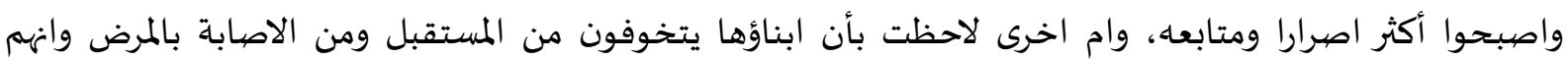

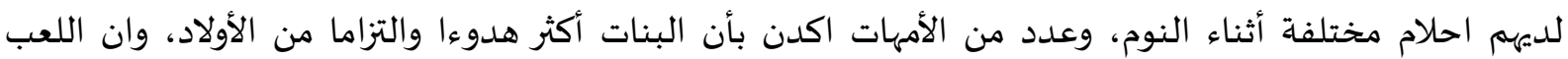

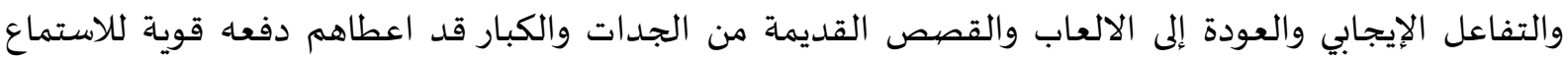
والانصات واعادة القصص والمواقف وتذكرها بشكل افضل، إضافة إلى سلوكيات عديده ظهرت على الإلى الأبناء كانت

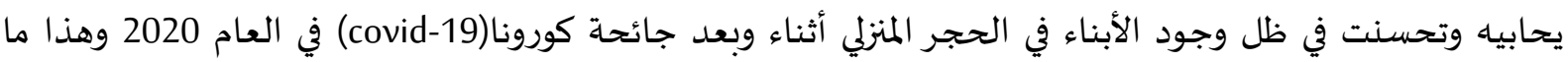
اشارت اليه دراسة Chandio-Ali-2019 بتأكيدها على الدور الإيجابي للأسرة في تحفيز نمو شخصية فئسية مستقرة ومعتدلة

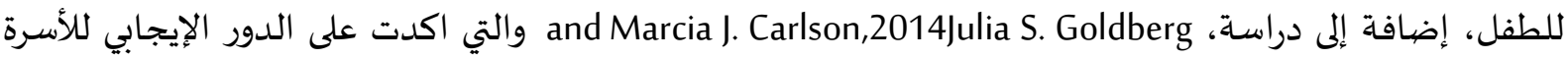
في تحفيزودعم الأبناء أثناء تواجدهم في المنزل. 
بناء على النتائج التي تم التوصل اليها يوصي الباحثان ويقترحان بما يلي:

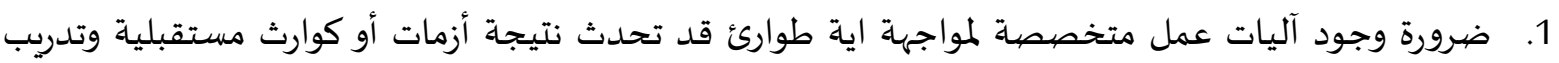

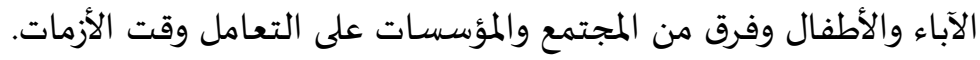
2. أن لا تغفل الجهات النافذة عن موضوع نشر الوعي واستخدام وسائل الاعلام والتكنولوجيا والذكاء الاصطناعي والمعلومات تحت الانذار المبكر وبسرعة التعامل مع الاحداث. 3. اما التوصية الاهم فتتعلق بالدور الذي يتطلب القيام به من الاهل والمربين في المنازل أثناء الأزمات واتخاذ الأداذ الإجراءات الصارمة خوفا من انتشار الامراض أو عدم السيطرة على المخاطر الناشئة نتيجة التراخي.

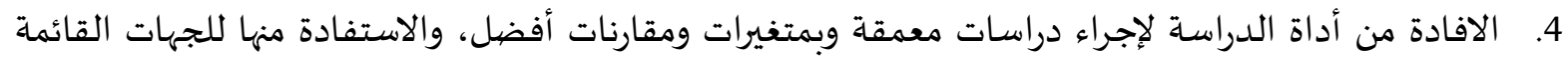

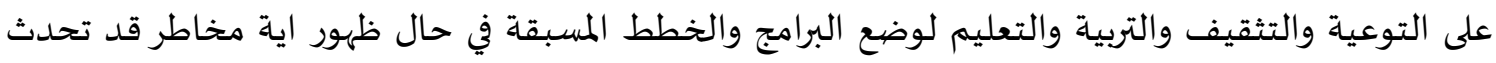

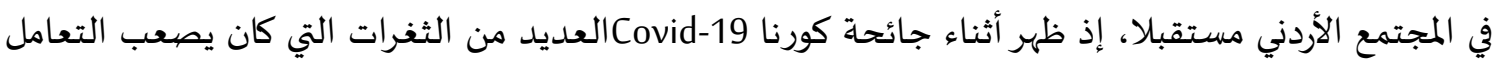
معها باعتبار انها المرة الأولى التي تواجهيها الأردن.

5. ضرورة إجراء المزيد من الدراسات حول ما تركته أزمة كورونا على الاسر والمجتمع والطلبة وخاصة الأطفال.

- باسمة حلاوة (2011) دور الوالدين في تكوين الشخصية الاجتماعية عند الأبناء "دراسة ميدانية في مدينة دمشق" مجلات جامعة دمشق -المجلد 27 -العدد الثالث + الرابع - - سعيد، صفاء (2020) أريك اريكسون ونظريته النمو النفسي - الاجتماعي، خلاصات، البوابة نت. - الظفيري، عبد الرحمن (2018) فاعلية برنامج مقترح لتنمية مهارات التربية الإيجابية لدى آباء الأطفال، مجلة كلية التربية، جامعة طنطا، المجلد 69 ج 1 العدد الأول. - - الفرخ، كامله وتيم، جابر (1999) الصحة النفسية للأطفال، دار صفاء للنشروالتوزيع، عمان الأردن.

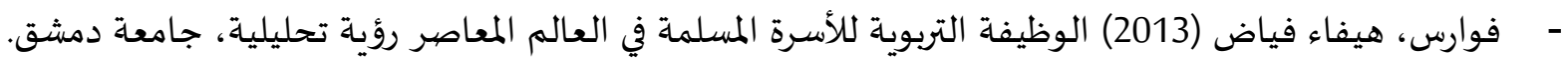
- المجلة البريطانية للطب النفسي (2019) - مجلة الجامعة الإسلامية للدراسات التربوية والنفسية، المجلد الحادي والعشرون، العدد الثالث، ص277 ـ -

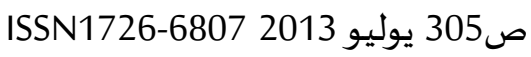

\section{ثانياً- المراجع بالإنجليزية:}

- Asonibare, F.B (2013) Family Cohesion and Level of communication between parents and Adolescent children, (Nigerian-journal of Guidance and Counseling-(V)11(N)1.

- BJP (2019) British Journal Psychiatric, London

- Charles A. Smith (1999)The Encyclopedia of Parenting Theory and Research, Edited by Greenwood Press, 
- Cowan, P. A., \& Cowan, C. P. (2002). What an intervention design reveals about how parents affect their children's academic achievement and behavior problems.

- J. G. Borkowski, S. L. Ramey, \& M. (2012) Monographs in Parenting and the child's world: Influences on academic, intellectual, and social-emotional development,Bristol-Power (Eds.), Lawrence Erlbaum Associates Publishers.

- Jane B. Brooks (2012) The Process of Parenting, Ninth edition, McGraw-Hill Education,

- Kerby T. A (2008) The Positive Parent: Raising Healthy, Happy, Successful Children, BirthAdolescence, Teachers College Press, to take the author's parenting tests.

- Matejevic M, Todorovic J, Jovanovic A.D: Family work patterns and dimensions of parenting style. Procedures - Social and Behavioral Sciences (141).

- Nelson, J. (2016) Positive Discipline guidelines. Retried from: https:// www positive discipline.com /articles / positive- discipline -guidelines.

- Siegelman. Rider, E (2015) Lifespan Human Development. Boston Cengage Learning.

- UN Covid-19Report 2020.

- visit http://MyParentingSkills.com and http://TeenParentingSkills.com

- WHO Report 2020. 